\title{
Planning for a renewable future in the Brazilian
} power system

\author{
Géremi Gilson Dranka ${ }^{a, b}$, Paula Ferreira ${ }^{c}$ \\ ${ }^{a}$ ALGORITMI Research Center, University of Minho, Guimarães, Portugal, geremidranka@ gmail.com \\ ${ }^{b}$ Department of Electrical Engineering, Federal University of Technology, Paraná, Pato Branco, Brazil \\ ${ }^{c}$ ALGORITMI Research Center University of Minho, Guimarães, Portugal, paulaf@dps.uminho.pt
}

\section{Abstract:}

The Brazilian electricity system is an important example of a large country relying on a high renewable energy matrix with a major focus on hydropower, which has historically allowed for low carbon electricity production. However, the increase in the demand and climate change impacts on the availability of these renewable resources represent important challenges for long-term power planning. The contribution of this paper is twofold: Firstly, a first attempt to use the EnergyPLAN model for the analysis of the Brazilian electricity sector and in particular to study future scenarios is presented. Secondly, the possibility of achieving a $100 \%$ RES system is also addressed. The $100 \%$ RES scenario is found to be theoretically possible but a substantial increase in the overall installed capacity would be required, to support the grid mainly during the spring and summer season. The results underline the importance of seasonal complementarity of hydro and wind power and reveal how an increase in RES would add exportation potential, reducing also the Brazilian external energy dependency. The study identifies risk factors for these high RES scenarios and outlines several avenues for future research to address cost, environmental and technical uncertainties of the system.

\section{Keywords:}

Brazilian Electricity Sector, Energy System Analysis, EnergyPLAN, Renewable Energy.

\section{Introduction}

The share of Renewable Energy Sources (RES) has increased substantially in the energy mix of developed and emerging countries as is the case of Brazil. This trend is expected to continue in the future, primarily aiming for the reduction of Greenhouse gas (GHG) emissions and mitigation of climate impacts [1]. The growth of energy consumption is also a common characteristic of most developing nations, including Brazil. Therefore, the prospects for achieving a sustainable energy system have been considered widely in literature and each year new studies are being published addressing different perspectives such as technological development, climate change and demand projections. RES to power is seen as a fundamental strategy to reach these sustainability goals, notwithstanding, there are several technical and economic challenges to be surpassed in order to achieve a high share of RES integration [1].

The proper construction of future scenarios for the electricity sector is fundamental to subsidize the government decision-making process. On the other side, the risks and uncertainties had increased in short, medium and mainly in the long-term [2]. Specifically, for the long-term generation expansion planning, the challenges are even greater primarily due to the characteristics inherent to the sector in which such decisions need to be made in advance. Energy planning is considered a complex issue that involves many factors and there can be no one size fits all solution, given the different challenges facing each country. This energy planning exercise will then result in a large discrepancy of scenarios, which depend on factors as cultural, economic and political ones, among others [3]. Regardless of this diversity of options and difficulties, scenario planning is fundamental for both policy making and the development of business strategies, mainly those relating to investments.

There are several challenges in the scenario's construction, especially for long-term planning. One of the main difficulties is to predict the behaviour over time of energy technologies that currently may not be feasible on a large scale or are not yet available. The definition of consistent hypotheses and the proper problem delimitation are also essential to achieve real and relevant scenarios. Furthermore, the design of a small number of future trajectories is desirable and demonstrates the relevance of the 
scenario-building technique for a well-informed decision making. [4]. Scenario analysis techniques are then well suited for the evaluation of impacts brought by the inclusion of RES technologies such as wind and solar power in the electricity system.

This paper aims to revisit the topic of high RES scenarios in developing countries with a high RES potential, as is the case of Brazil (classified as an Emerging Market and Developing Economy by International Monetary Fund [5]) analysing and comparing different future scenarios (for the year 2050) previously developed by reliable energy research institutions. The possibility of achieving a $100 \%$ RES system in Brazil is also addressed in this paper. The vision presented here is the development of a comprehensive comparison among these three future scenarios according to different perspectives including technical, cost, environmental and risk dimensions. Although a few papers have recently addressed the case of a 100\% RES in Brazil, less attention has been paid to both the exportation electricity potential for scenarios with a high share of RES and the seasonal complementarity between power options such as hydro and wind power (for the case of Brazil). Considering both the high share of RES and the continental dimensions of the Brazilian electricity system, this paper includes partially the geographical heterogeneity of the country in order to achieve more reliable results. Also, the short-term impacts are becoming increasingly important to consider in the long-term planning. The computational barriers associated with large power systems, however, have limited the inclusion of short-term impacts in long-term planning models [6]. The tool used in this paper (EnergyPLAN) allows to consider high time resolution for an entire year using hourly timesteps [7].

Therefore, the following two research questions has been used to provide a clearer goal of the paper:

1. How can the Brazilian electricity system be modelled in the EnergyPLAN computer model?

2. Can a $100 \%$ renewable energy system be achieved by 2050 for Brazil?

The paper is organized as follows. Section 2 outlines the main characteristics of the Brazilian electricity system. A literature review regarding energy scenarios for high RES systems is presented in Section 3 together with the EnergyPLAN model description. Section 4 introduces the methodology proposed for applying EnergyPLAN model concerning the Brazilian electricity sector. The reference energy system and the future scenario analysis (2050) are presented in section 5 (results and discussion) together with the simulation and evaluation of a 100\% RES using technical and economic analysis. The main conclusions and directions for future research will be outlined in section 6 .

\section{The Brazilian Electricity System}

The absence of exploitable natural resources is expected to be a future characteristic common to the most of countries worldwide. Thus, the reliance on fossil fuels for the energy sector becomes particularly vulnerable to fuel price fluctuations [1]. On the other hand, the Brazilian electricity system is mostly supplied by hydropower. Hydroelectricity presents many advantages over other power sources, including high efficiency, large storage capacity, low operating and maintaining costs, a high level of reliability and proven technology. Hydropower is also considered the least-cost renewable electricity technology even though the projects require substantial investments [8]. For the Brazilian National Power Grid Operator (in Portuguese, ONS), hydroelectricity is a valuable power source especially given the rapid growth of variable and intermittent generation from other RES, namely wind and solar power technologies. The hydropower generation system in Brazil comprises large reservoirs capable of multi-month regulation, which is arranged in complex cascades distributed in several river basins [8]. In the future, the increasing share of several complementary non-hydro RES is expected to diminish the dependency on hydropower and drive to possible least-cost solutions [9].

The estimated total hydropower potential of the country is about $260 \mathrm{GW}$ [10] and in 2017 (April) the exploited potential slightly exceeded $101 \mathrm{GW}$, meaning that more than $50 \%$ remains unexplored. Nevertheless, the hydropower expansion faces several environmental challenges which together with the high dependency of rainfall and climate conditions, can severely affect the future expansion of hydropower for energy production [2]. Even though the remaining unexploited hydropower potential 
in Brazil, the future projects are expected to be dominated by run-of-river hydropower with limited reservoir capacity. Thus, the challenge is to provide a high level of flexibility from other power sources and from energy storage technologies that might be capable of linking geographic and temporal (daily, weekly and seasonal basis) gaps between energy supply and demand [11]. The water resource availability due to climate changes is assuming a key role in the Brazilian energy planning and has been widely discussed in the literature $[9,12]$. Therefore, wind and solar energy systems have been increasing rapidly over the last years. Brazil has a great potential for the development of solar energy with one of the highest insolation rates worldwide, however, this potential has been underused. Fig. 1 illustrates the historical power output (left axis) and the Southwest ${ }^{1}$ hydro storage level (right axis) in Brazil from 2000 to February 2018 (Southwest region represents $40 \%$ of the total hydropower of the country). After the severe drought in 2001, the Brazilian government decided to support the development of non-hydro RES as an alternative to the historic dependence on hydropower. In fact, since 2009 auctions have been made exclusively for wind and solar PV systems, which increased the share of non-hydro RES in the country's energy mix [9].

75000

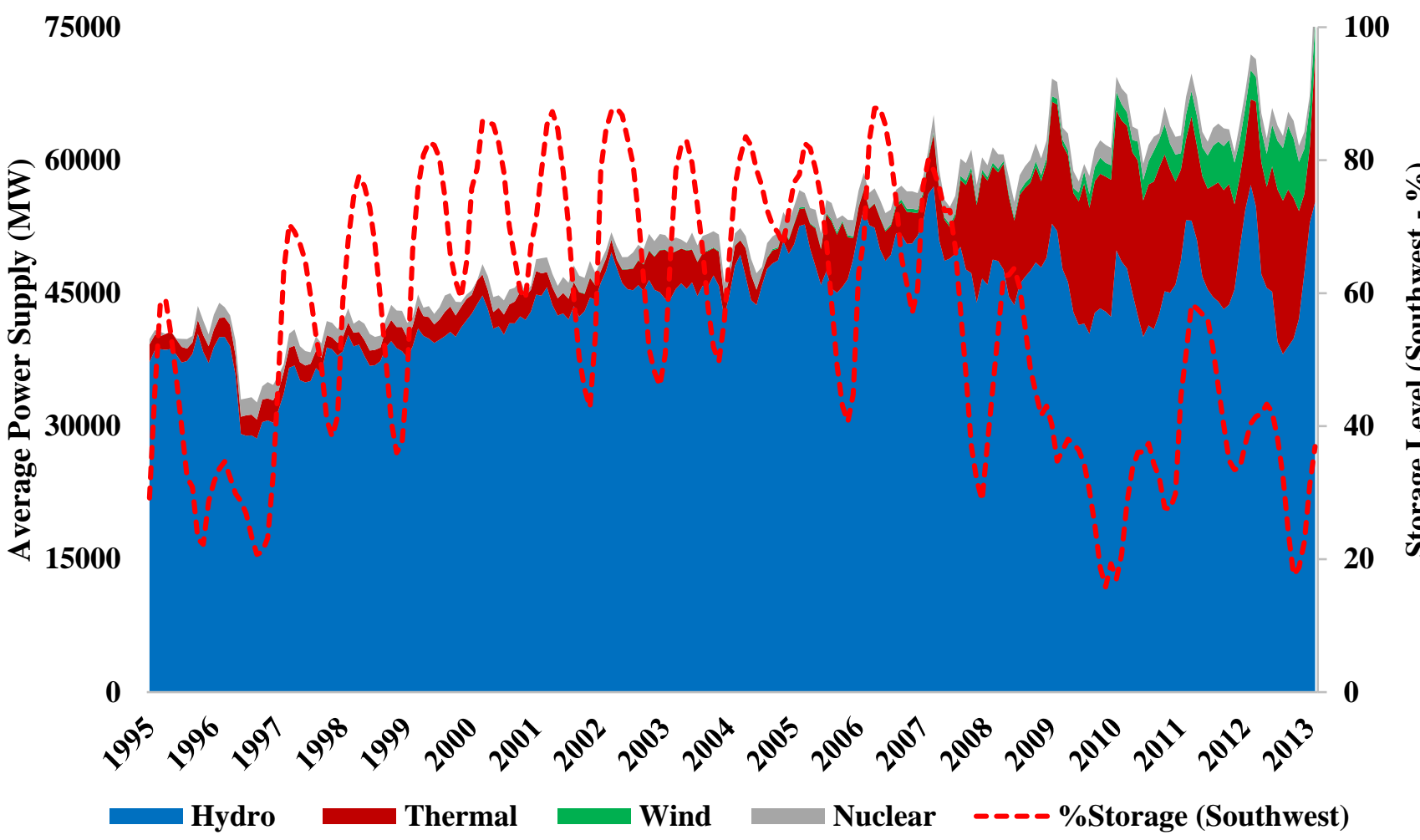

Fig. 1. Brazilian power output between 2000 and 2018 (February) (left axis) and water storage level in SE (right axis).

The Brazilian hydropower capacity is $101.28 \mathrm{GW}$, representing $64 \%$ of the total installed capacity of the country [13]. The remaining electricity supply for Brazil has been provided mostly from thermal power generation. Brazilian electricity generation reached 578.9 TWh in 2016 [16]. In 2016, hydropower installed capacity increased by more than 55\% comparatively to 2015 , followed by an increase of less than $27 \%$ for solar and wind and slightly more than $18 \%$ for the case of thermal power [16]. According to the National Energy Balance (in Portuguese, BEN), in 2016, 81.7\% of the Brazilian electricity supply was composed by RES, including $68.1 \%$ of hydropower; $8.2 \%$ biomass; $5.4 \%$ wind and $0.01 \%$ from solar PV [16]. Consequently, considering the increasing growth rate in energy consumption, expected to be about $3.7 \%$ per year for the period 2016-2026, new investments

\footnotetext{
${ }^{1}$ Technically, the Southwest hydropower system comprises both Southwest and Midwest Brazilian regions.
} 
127 are being considered to expand the power grid [15]. According to the national energy plan of 2026, 12845 billion of US dollar ${ }^{2}$ is estimated to be invested between 2020 and 2026 for the expansion of the 129 Brazilian generation system [15].

130 Additionally, Brazil has been undergoing severe droughts (mainly in the Southeast, Midwest, and 131 Northeast) since 2012, leading to an increase of generation from thermal power (see Fig. 1) [5,6]. 132 This thermal power trend remained for the latter years (2013 to 2017). Particularly, the amount of natural gas imported has significantly increased in these years to supply thermal generation [15]. Therefore, the marginal cost of electricity production enhanced significantly in the last years [16].

Between 1999 and 2011, the average power output of thermal power plants was about 2425 MW whereas between 2012 and 2016 this value increased significantly to 10947 MW [17]. The aforementioned increase in thermal generation is primarily due to a reduction in the maximum energy storage capacity of hydropower over the years mainly for Southeast (SE), Midwest (CO) and Northeast (NE) Brazilian subsystems. The SE and CO regions represent approximately $70 \%$ of the total water storage capacity in Brazil and the maximum water storage level has been verified historically between March and April whereas the minimum storage usually occurs between October and November [16].

Additionally, the high level of uncertainty brought by intermittent sources will result in an overall trend to the increase of the thermal generation in the future. Thus, the thermal power plants are expected to play an essential role in the next years, mainly between September and December, due to the lower hydropower storage level [15]. Therefore, for the next years, a paradigm shift in the Brazilian power operation and planning is foreseen, which requires an in deep discussion in order to provide a high level of energy security and reliability [2].

Conclusively, the large-scale integration of RES in Brazilian electricity sector faces several challenges and involves a radical technological change. From a technical point of view, the most important question to be answered is related to which technologies should be used to make sure that the available resources would meet the demands in the future. Moreover, the intermittent nature of some RES, such as solar PV and wind systems, has become a significant challenge to the power system operation and planning [18]. According to [19] the transition to a renewable energy system from traditional fossil-fuel based systems includes modifications in energy efficiency and energy conservation, improvement of the efficiency of the supply system and integration of fluctuating RES.

\section{7}

\section{Energy scenarios for high RES systems}

The work proposed by [9] considered a 100\% RES for Brazil in the year 2030 considering the set of technologies available, mix of capacities, operation modes and the least cost energy supply. This paper simulated the operation of Brazilian electricity system on an hourly basis and used a multi-node approach. The model was based on a linear optimization problem aiming to minimize the total annual energy system cost and considers the inclusion of Distributed Generation (DG) and self-consumption of residential, commercial and industrial electricity consumers. The results obtained by [9] showed that the required overall installed power capacity in 2030 would be $165 \mathrm{GW}$ from solar PV, hydroelectric dams $(85 \mathrm{GW})$, run-of-river hydropower $(12 \mathrm{GW})$, biomass $(12 \mathrm{GW})$, biogas (12 $\mathrm{GW})$ and $8 \mathrm{GW}$ of wind power.

In [20] the least-cost power system composition of a 100\% RES for the year 2050 is addressed for the Brazilian power sector. The authors also appraise the effect of sector coupling (i.e. power, heat and transport sectors) on the Brazilian power system. The high-resolution model REMix was applied in [20] making use of a linear programming optimization model to identify the least-cost power system composition considering the use of storage technologies, DR contribution, electric mobility and hydrogen production. According to the results of [20] the expansion of wind and solar power might be more cost efficient in the future than the construction of new hydropower plants in Brazil since the hydropower system (even considering that only run-of-river power plants are being

${ }^{2}$ One Brazilian Real (R\$) is equivalent to 0.26 United States (US) Dollar (July 13, 2018). 
projected for the future) might provide enough storage capacity to compensate the high integration of RES. The authors of [20] also concluded that neither varying the share of wind and solar power nor the spatial distribution of power generation would have major impacts on the overall supply costs. Therefore, other criteria could be used to promote the renewable energy transition towards a $100 \%$ RES such as public acceptance so that this would have only a small influence on system costs.

The comparison among different strategies to transform the heating sector of Denmark into a $100 \%$ renewable energy system is addressed in [21] resourcing the advanced energy system analysis tool EnergyPLAN. A methodology to link local and national planning is proposed in [22]. This proposed methodology evaluates how well the system can exchange excess electricity. Ref. [23] compares two $100 \%$ RES systems. The first scenario proposed by [23] considers a non-integrated renewable energy system while the second scenario is based on the smart energy system concept in which the synergies between other sectors are taking into account for Zabreg. Also for Croatia, a 100\% local RES for the year 2050 is proposed by [24] considering the electricity, heating and transport sectors. The work also analyses the integration of the local energy system with the rest of the country.

In the transition to a fully decarbonized RES, the high amount of fluctuating renewable energy such two potential ways to increase power system flexibility: the interconnection between power systems and the integration of different sectors of an energy system such as heat and electricity. The authors of [25] derived broadly applicable conclusions on the benefits and role of the energy system integration and highlight that this option should be prioritized over the expansion of transmission systems for the case-study evaluated.

\subsection{The EnergyPLAN model}

There are several energy modelling tools available to design national energy planning strategies considering technical and/or economic analysis. The EnergyPLAN advanced energy system analysis computer model [26] has been widely used to simulate future energy scenarios, focusing primarily in the large-scale integration of RES into the power system and in the simulation of $100 \%$ renewable energy systems as proposed in [11] and [18]. The EnergyPLAN allows to simulate the operation of national or regional energy systems on an hourly basis taking into account the hourly demand, expected production and interconnection capacity. This tool makes use of analytic programming instead of iteration.

The work proposed by [27] reviewed forty-five papers that applied the EnergyPLAN model and concluded that most of the papers performed analysis on a country or state level and the focus is mostly in the simulation and high integration of RES into the energy system. There are existing models already available for many countries, including China, Croatia, Czech Republic, Denmark, Finland, Hungary, Ireland, Italy, Kenya, Latvia, Macedonia, Mexico, New Zealand, Norway, Romania, Serbia, Sweden, Tanzania, Turkey and United Kingdom [26]. The study of an energy system based entirely on renewable energy resources has been also addressed in the literature using the EnergyPLAN model. Most of the past works considered the analysis of $100 \%$ renewable energy systems for developed countries, including Finland [11], Macedonia [18] and Portugal [28]. In [11], the authors employed the EnergyPLAN model to verify the possibility of implementing a $100 \%$ renewable energy system in Finland for 2050 and pointed out the importance of Energy Storage Systems (ESS), including Thermal Energy Storage (TES), Gas storage, Power-to-Gas (PtG) technologies and Vehicle-to-Grid (V2G) connections to achieve a fully decarbonized energy system.

In [1], the authors emphasize that energy efficiency and demand-side measures are essential to achieving a $100 \%$ renewable energy system. The prospects for the realization of a fully renewable energy system in Macedonia was performed in [18] using the EnergyPLAN model. The work considered scenarios for the year 2030 (50\% RES) and 2050 (100\% RES) and the authors concluded that the intermittent characteristic of RES and the large-scale insertion of storage technologies are considered the main obstacles to achieving a 100\% renewable energy system. The authors of [28] concluded that the fully decarbonized electricity system for Portugal is theoretically possible but a substantial increase on both the overall system capacity and the costs would be necessary. 
On the other hand, according to [26] and considering the best of authors' knowledge, thus far the including Brazil. For the Brazilian case, this may be understood by some aspects, namely the difficulty in collecting hourly data for demand and supply, the high level of complexity required for aggregating information to be included in the model and the Brazilian continental dimensions.

Therefore, this work presents the first-stage results of an EnergyPLAN model for the analysis of the Brazilian electricity sector. For this purpose, the year of 2016 was used to validate the model. Afterwards, future existing scenarios (for the year 2050) obtained from reliable institutions of the electrical sector were evaluated. A comparison of the results obtained from EnergyPLAN and those from the Brazilian institution was attempted. The possibility of achieving a 100\% RES system is also addressed in this paper together with a risk and resilience analysis of the future electricity scenarios. The analysis of a fully renewable electricity system aims to provide some insights into the impacts of high amounts of Variable Renewable Energy (VRE) on the power grid and supply costs.

\section{Methodology}

A critical literature review was firstly undertaken to provide the necessary background knowledge of previously published research in the area and to establish the boundaries of the research. Information was collected from official reports and scientific literature, addressing the case of Brazil. From this a set of scenarios recently published for the case of the Brazilian electricity system were identified and characterized.

The data collection techniques include an examination of multiple-source secondary data and online computer databases from official electricity Brazilian institutions to simulate an energy system in EnergyPLAN. The first step was to create a reference model using technical input considering a past year. The inputs for the model were established based on the projections for hourly demand, hydropower inflows, hourly import and export balance, interconnection capacity, installed capacity of thermal power plants, and RES technologies. The reference model was used to validate the model, comparing the simulated outputs to the real ones for each technology/generation option and for each region.

The most recent data available concerning the total annual demand ( $\mathrm{TWh} / \mathrm{year}$ ) and its hourly distribution for the Brazilian electricity sector report to the year 2016, and were obtained from the Brazilian National Power Grid Operator (ONS) [17]. For the same year, the capacity of each installed unit (MW) was extracted from the Energy National Balance (in Portuguese, BEN) [29]. Hydropower was divided into run-of-river (54\%) and hydro plants with reservoirs (46\%). Thermal power plants were represented in EnergyPLAN as the sum of natural gas, oil products, coal and biomass installed capacities, whereas the installed capacity of nuclear power plants was represented separately. The overall demand of the country was aggregated based on [17] since the EnergyPLAN model does not allow to consider individual demands for the electricity sector and transmission restriction between regions. However, due to its continental dimensions, the country was branched into three main regions (South, Southwest and Mid-West, Northeast and North) in order to represent the installed capacity for wind and solar PV. The installed capacity for the other renewable power sources was not grouped by region due to technical limitations of the EnergyPLAN software. Therefore, it was chosen to branch the installed capacity for the two most promising RES-based power sources for 2050 (i.e. wind and solar power), according to [30]. Values for the interconnection capacity with neighboring countries are based on the current and future projections supported by [31] and [32].

Hourly power output from wind and solar PV were obtained using an online application available on [33] based on [34] and [35], and using weather information of the last 30 years collected by NASA. Hourly distribution for nuclear power plant was adapted from a daily curve obtained in [17]. For thermal and hydropower (run-of-river), the hourly distributions were obtained directly from ONS. The maximum storage capacity for dammed hydro (GWh) was obtained from [17] and calculated from the sum of the maximum hydropower storage capacity (monthly) of each subsystem and the 
water hydro supply for hydro plants with reservoirs, which corresponds to the sum of affluent natural energy of each subsystem, obtained from [17].

For all the scenarios evaluated, the high share of wind power occurs in the Northwest, far from the load centers of the country. This would imply a significant increase in power transmission capacities and consequently in the overall system costs. However, for the sake of simplicity, the proposed model does not take into account the cost related to new transmission lines and the restrictions related to interconnections between Brazilian subsystems on the simulations.

EnergyPLAN estimates the hourly production of each intermittent RES (e.g. run-of-river, wind and solar power) based on both the installed capacity and the hourly distribution. The model output consists of annual energy balances, fuel consumption, $\mathrm{CO}_{2}$ emissions and cost analysis.

Future scenarios are available on [30] and the document is entitled as "Brazilian Energy Scenarios for 2050". Four different institutions of the Brazilian power sector developed those scenarios, namely COPPE (in Portuguese, Instituto Alberto Luiz Coimbra de Pós-Graduação e Pesquisa de Engenharia), ITA (in Portuguese, Instituto Tecnológico de Aeronáutica), SATC (in Portuguese, Associação Brasileira do Carvão Mineral) and Greenpeace. For the sake of simplicity, this study will focus on analysing the scenarios proposed by COPPE and Greenpeace. The analysed scenarios were then established as follows:

1. Reference scenario for model validation: This scenario was attempted based on 2016 as the reference year.

2. Scenario 1 (COPPE): Scenario for 2050 based on input data presented in [30,36].

3. Scenario 2 (Greenpeace): Scenario for 2050 based on input data presented in $[30,36]$.

4. Scenario 3 (100\% RES): $100 \%$ renewable electricity scenario for 2050 . This scenario was elaborated by the authors based on [10,20,30,36,37].

Fig. 2 summarizes the methodological approach applied in this research. The data used for modelling are displayed in Table A.1 (Appendix A), for the reference model and for the future scenarios. For all the future scenarios, projections for the total electricity demand were based on [36].

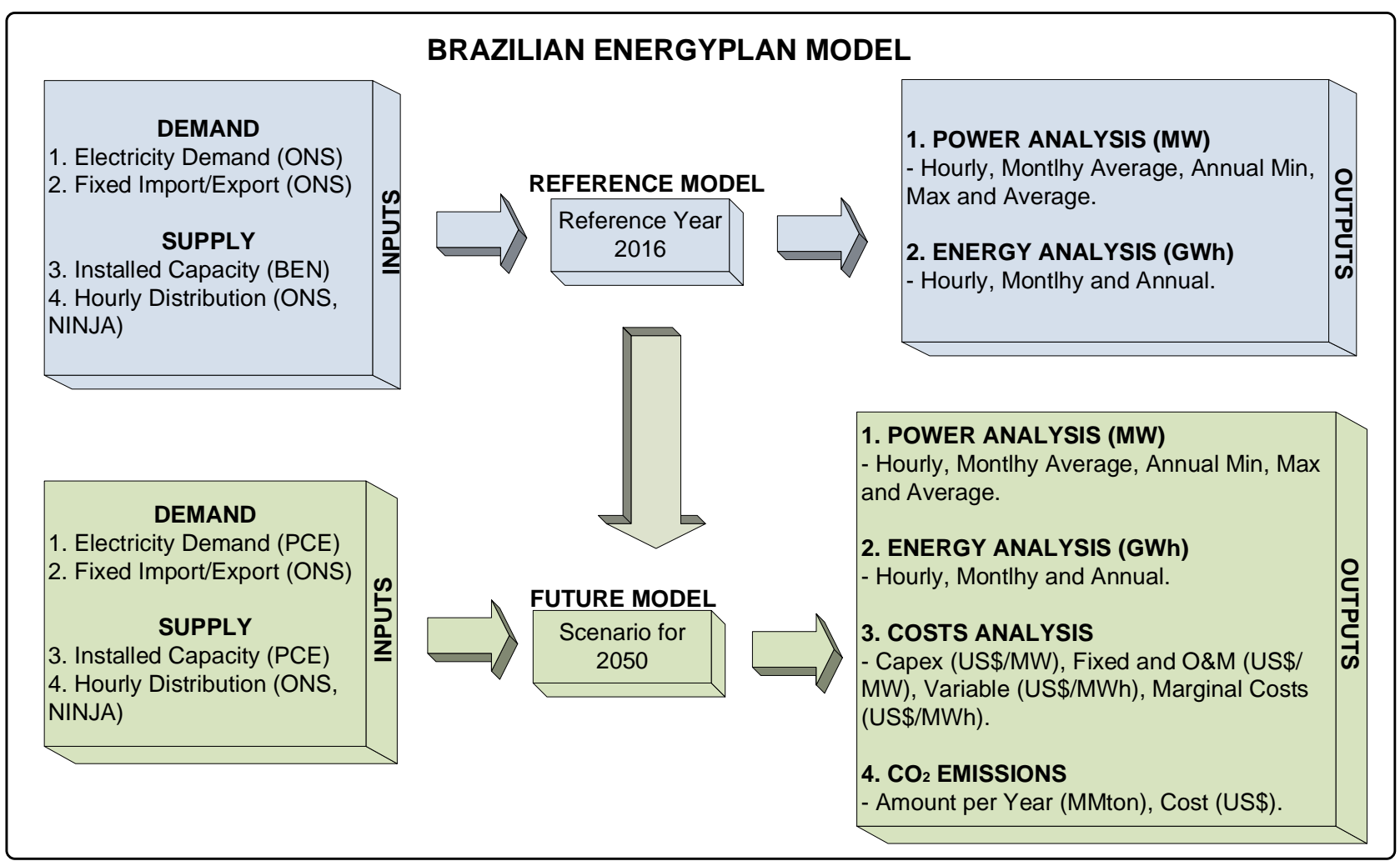

Fig. 2. The methodological approach of the research. 
The choice for using the advanced energy system analysis tool EnergyPLAN in this research includes the following benefits of the tool [21]: i) the high time resolution (simulating an entire year using hourly time-steps); ii) the high degree of credibility; iii) the replication of the results may be performed easily by other researchers and iv) the tool is freeware and comes in a user friendly interface. The EnergyPLAN model description and the detailed documentation of the tool can be found in Refs [7,38].

\section{Results and Discussion}

In this section, scenarios are evaluated considering technical and economic analyses of the overall system using the proposed methodology. For analyses and comparison of scenarios, EnergyPLAN model is applied. Section 5.1 presents the reference energy system (2016) used to validate the model. Afterwards, in Section 5.2 future scenarios (for the year 2050) previously proposed by reliable institutions of the electrical sector [30,36] will be analysed, addressing, in particular, the energy generation mix and power output of different technologies. The analysis of a $100 \%$ renewable electricity system for Brazil is undertaken in section 5.3. A sensitivity analysis is undertaken in Section 5.4 for all scenarios, addressing the case of critical water shortage. Section 5.5 provides a socioeconomic analysis, including the calculation of marginal costs, Levelized Cost of Electricity (LCOE) and total $\mathrm{CO}_{2}$ emissions. Finally, section 5.6 provides an in-depth critical discussion and assessment of the results and findings of the scenarios analysed.

\subsection{Reference Scenario and Model Validation}

The main objective of this section is to validate the model to further evaluate the future scenarios. For this purpose, the year 2016 was used as the reference scenario. The inputs for the EnergyPLAN model were established according to section 2 and are presented in Table A.1 (Appendix A). Fig. 3 illustrates the monthly electricity production for the Brazilian power system in 2016 considering the real data operation extracted from ONS [17] and the EnergyPLAN model results according to the methodological approach proposed. In the Fig. 3, EP is the abbreviation for EnergyPLAN.

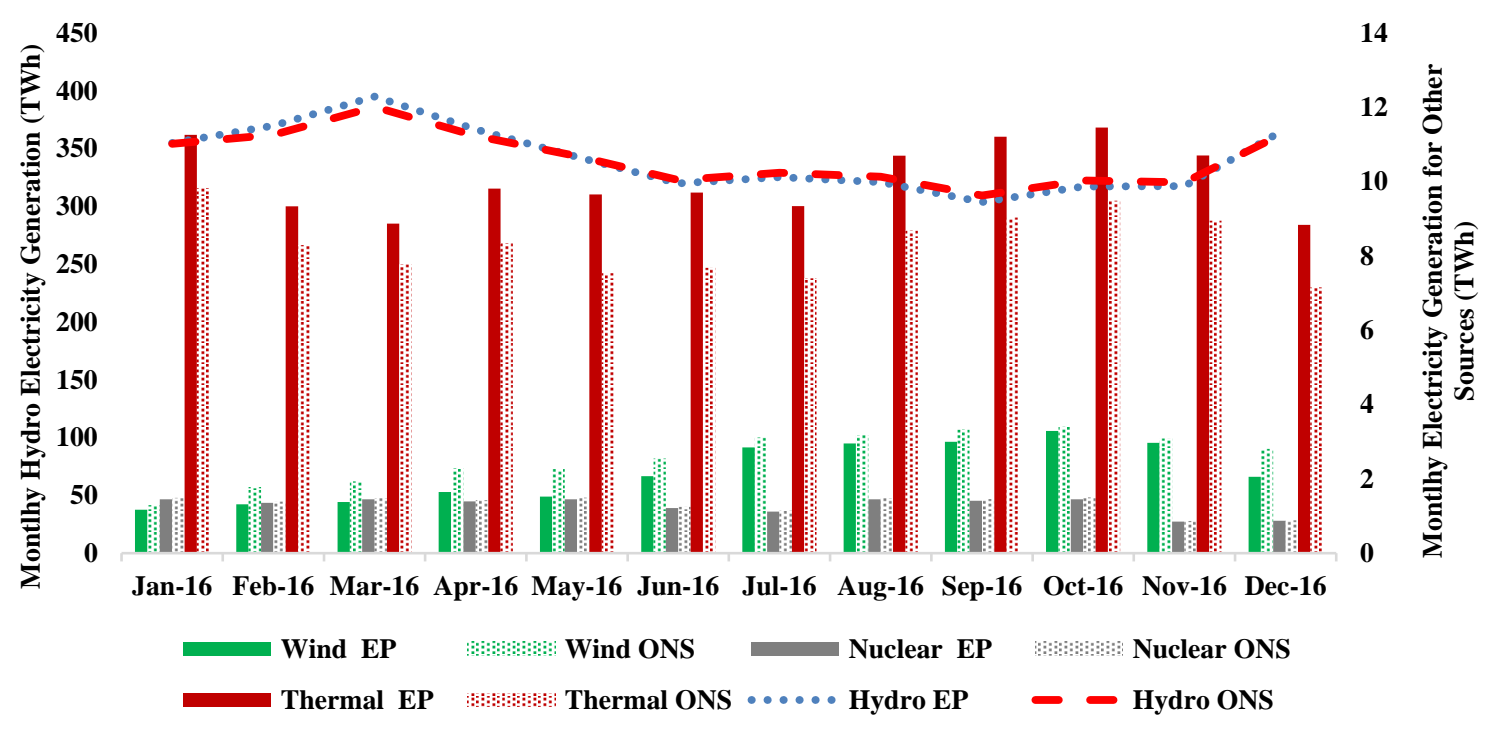

Fig. 3. Monthly electricity production for the Brazilian power system in 2016.

Given the variable and intermittent nature of RES (e.g. wind and sun), the dispatch of these plants can only be predicted and not planned. This feature is considered in the simulation procedure undertaken by EnergyPLAN model. Therefore, solar, wind, run-of-river, wave power and tidal are considered as non-dispatchable sources in EnergyPLAN. 
The monthly values of hydropower generation obtained through EnergyPLAN revealed to be similar to the real data as illustrated in Fig. 3. The maximum monthly error (measured as the difference between real ONS data and the simulated ones with EP) obtained for hydropower was approximately 2.3\% (March). For nuclear and thermal generation, the maximum monthly errors obtained were respectively 3.16\% (May) and 9.99\% (December). Even considering three main Brazilian regions (the maximum number allowed in the EnergyPLAN model), the error for intermittent RES (wind and solar power) is expected to be higher comparatively to the one obtained for the other sources. It is worth recalling that information for wind and solar power was obtained from typical values from the literature [33] and not for the specific case of 2016, which will influence this error. Furthermore, the difference in the average values of the wind speed at different heights and types of wind turbines enhances the complexity of the analysis. Even so, the annual medium error obtained for wind was slightly higher than $15 \%$ and the maximum monthly error was near 32\% (on May), which was considered to be acceptable given the simulated and long-term nature of the study.

The hourly dispatch of hydro and thermal power differ in some extent to the real dispatch. This fact can be explained by the different factors which condition the real hydro power output and cannot be fully captured by the technical nature of EnergyPLAN, namely the water inflows downstream and upstream, minimum and maximum volume restrictions and real turbinated inflows which can be variable seasonally due to environmental protection and flood control measures.

The hourly data for solar PV generation is not considered for this reference scenario due to its low installed capacity $(0.01 \%)$ in the year 2016.

Therefore, the main objective of this section was to validate the model considering a reference scenario. The monthly absolute percent discrepancy between modelled and real data for each power source was described along this section. The results obtained allowed to conclude the accuracy of the obtained results and this was confirmed by comparing the obtained simulation results to the real data collected in [17]. The annual percent error is smaller than the average monthly error mainly because the uncertainties (e.g. the stochastic and intermittent characteristic of RES) but also because the particular strategic dispatch characteristics of the National Grid Operator that cannot be fully captured by the EnergyPLAN. These uncertainties combined lead to small errors for the entire year which can be considered acceptable considering the long-term nature of the study. The analysis of the monthly error is considered particularly important since it becomes possible to analyse more accurately the probable implications of seasonal patterns in electricity generation from RES and thermal sources.

\subsection{Brazilian Electricity System Analysis for $\mathbf{2 0 5 0}$}

This section aims to describe the use of Brazilian EnergyPLAN model to analyse future electricity scenarios, as described in section 3. According to [39] hydroelectric power plants alone, will not be able to guarantee the security and reliability of energy supply in the future. For simulating the energy scenario for 2050, a correction factor is then considered to represent run-of-river power plants. This means the capacity factor of hydropower is expected to reduce from 0.49 in 2016 to an estimated value of 0.39 in 2050 according to [30]. This reduction should occur mainly due to climate changes and the characteristics of the target rivers, as most part of the unexploited resources are in the Amazon River basins in which the projects are expected to be dominated by run-of-river power plants [39].

Fig. 4 illustrates the share of electricity generation for each source considering the real data for the reference scenario [17], published scenarios for 2050 [30] and its corresponding results obtained through the EnergyPLAN model. In the Fig. 4, data for solar energy comprises PV systems, Concentrated Solar Power (CSP) and rooftop PV systems, whereas thermal includes biomass, natural gas, coal, fuel oil and industrial gas. 


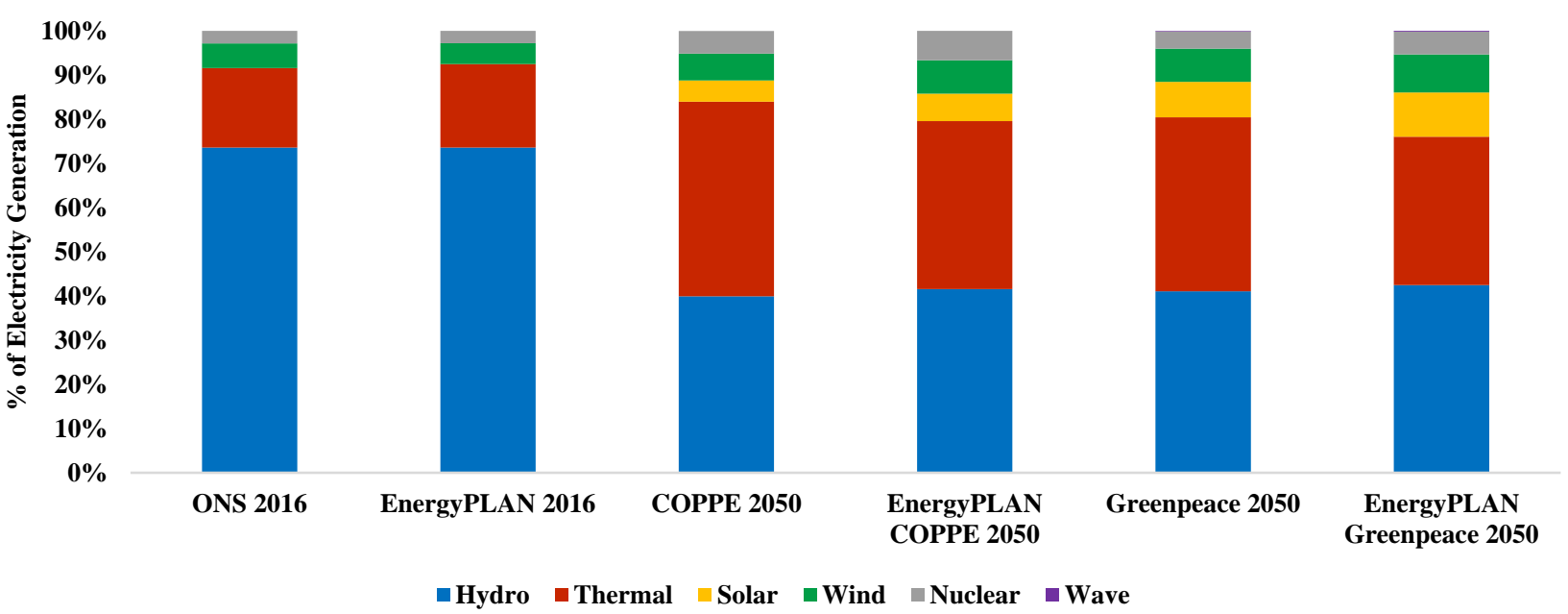

Fig. 4. Annual electricity production for the reference and future scenarios.

383 According to historical data, the maximum water storage level usually occurs between March and April (autumn) whereas the minimum storage is generally reached between October and November (spring) [16], [17]. Thus, considering that Brazil's electricity supply consists primarily of hydropower, the results will focus on analysing the hourly data from two pre-selected weeks corresponding to the minimum and maximum water storage cases. Fig. 5 illustrates the hourly electricity production on an autumn week for: a) COPPE scenario and b) Greenpeace scenario.

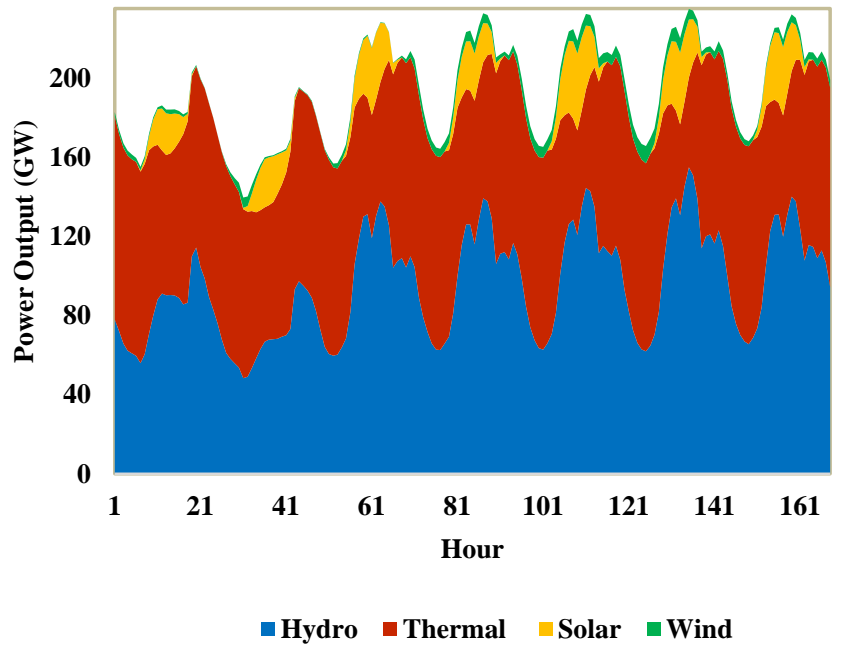

(a)

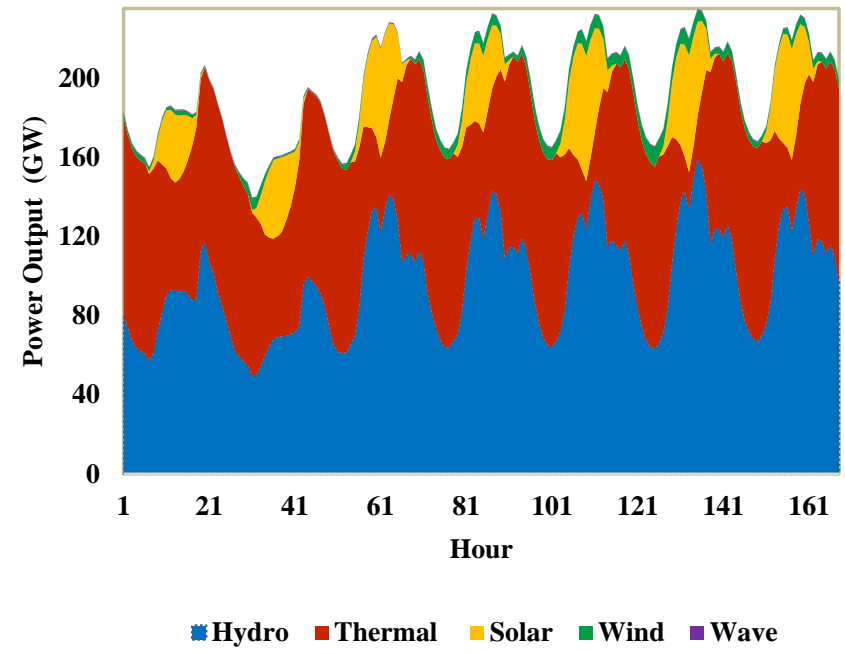

(b)

Fig. 5. Power output on an autumn week for: a) COPPE scenario, b) Greenpeace scenario.

393 The hourly electricity production on a spring week for: a) COPPE scenario and b) Greenpeace scenario is illustrated in Fig. 6. 


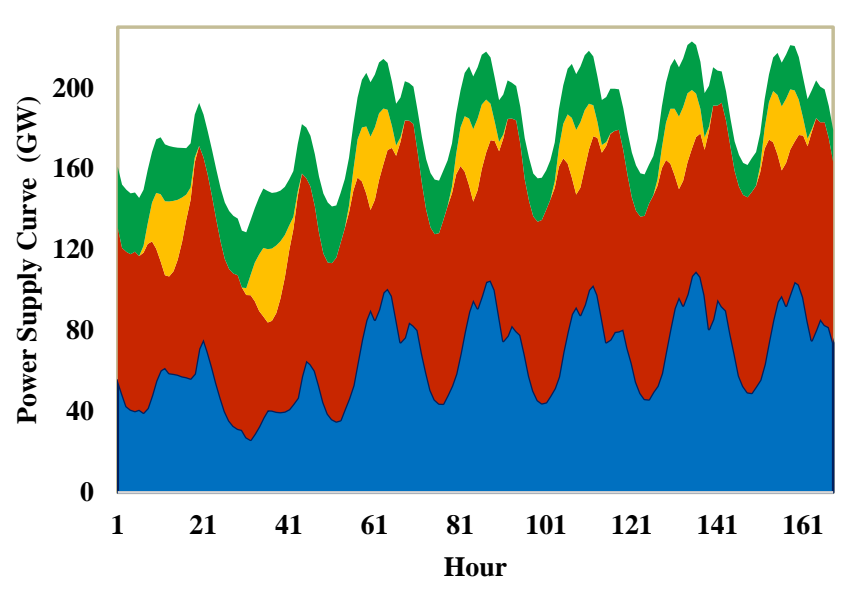

口Hydro $\square$ Thermal Solar $\square$ Wind

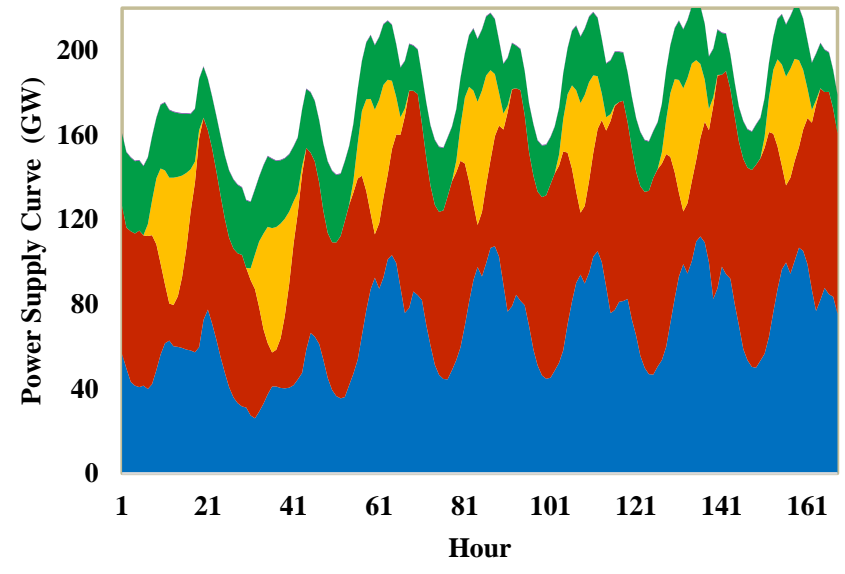

\#ydro $\square$ Thermal Solar $\square$ Wind $\square$ Wave

(a)

Fig. 6. Power output on a spring week for: a) COPPE scenario, b) Greenpeace scenario.

The results indicate that solar power will also have a determinant role and will contribute to moderate considerably the thermal generation in 2050. For the COPPE scenario, considering the peak power from solar generation at midday (April, 06- autumn), the solar PV contribution to the system would represent about $17.41 \%$, wind $2.72 \%$, hydro $57.20 \%$ and the additional electricity would be generated by thermal power plants (22.66\%). For this case, RES supply would represent approximately $77.34 \%$ of total electricity production. Clearly, it is possible to see that solar power production contributes to reduce thermal power use, primarily during peak sun-hours. As for the full day, the total amount of electricity would be generated from hydro $(51.06 \%)$, from wind $(2.75 \%)$, thermal power $(40.06 \%)$ and solar power $(6.12 \%)$. It is important to note that EnergyPLAN does not allow to take into account the cyclical characteristics of thermal power plants, e.g., maximum thermal ramp rate. In this case, for instance, thermal generation decreased from $95139 \mathrm{MW}$ to $22272 \mathrm{MW}$ in six hours with a ramp rate of $12.1 \mathrm{GW} / \mathrm{h}$. This feature should be better evaluated in future works, estimating the impact of a high RES share on thermal power operating conditions at a country scale, as discussed for example in [40] at a regional scale.

It is worth mentioning that the installed capacity of solar power according to Greenpeace scenario is expected to be greater $(18.87 \%)$ than the one obtained for the COPPE scenario $(12.95 \%)$. Therefore, from Fig. 5 and Fig. 6 the higher contribution of solar production for Greenpeace becomes evident. For instance, during some hours of the week, the solar production is even higher than the one from thermal generation. Besides the complementarity between wind and hydropower, complementarity between solar and wind power also emerge for this case. Specifically, Fig. 5 shows that during the autumn week, solar PV has a high potential but low wind power output is observed. The opposite situation occurs for the spring week case.

For both hydro and thermal generation, the differences between EnergyPLAN and COPPE and Greenpeace scenarios are smaller than for wind and solar power. Specifically, for wind and solar power, the total annual amount of electricity obtained from EnergyPLAN is higher than the one estimated for both COPPE and Greenpeace scenarios.

For a typical week of April (autumn), the generation from wind source is lower than the one on a typical week of November (spring), according to the assumed wind profile data. This pattern is typical for the first months of the year as illustrated in Fig. 7, which represents monthly hydro and wind power electricity production for the COPPE scenario. Historical real data for years 2015-2017 retrieved from ONS [17] shows that this monthly profile is well evident for both hydropower and wind power. In the Fig. 7, the axis for electricity generation from hydro (on the left) and wind (on the right) are intentionally presented in different scales since the objective is to highlight the complementarity between both hydro and wind power sources in different seasons. This 
complementarity is expected to play a key role for large wind power scenarios foreseen for the Brazilian electricity system.

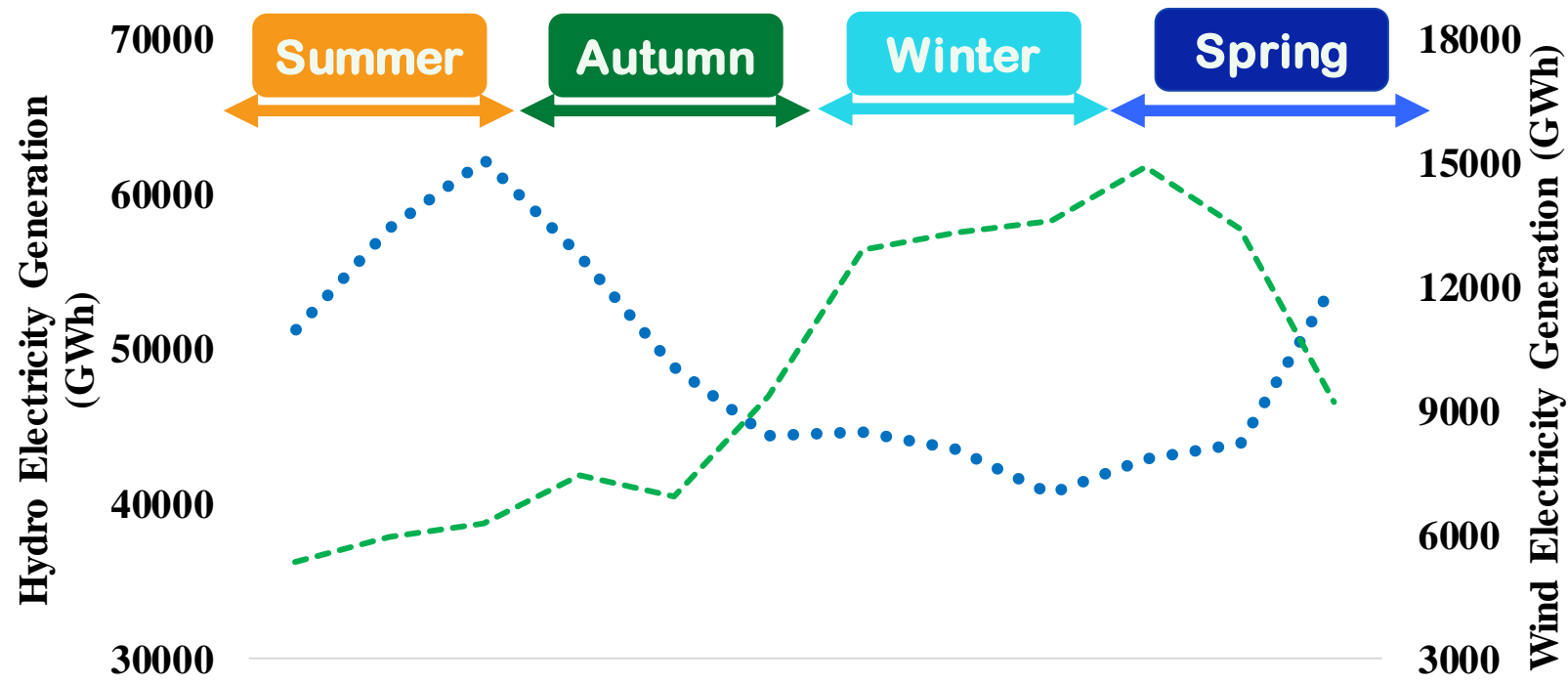

Jan Feb Mar Apr May Jun Jul Aug Sep Oct Nov Dec -. Hydro EP --- Wind EP

Fig. 7. Hydro and wind power electricity production for COPPE scenario.

Conclusively, the future electricity scenarios were analysed in this section considering the technical analysis. The results obtained by the EnergyPLAN model were compared to the published scenarios for 2050 [30]. Two weeks of the year were selected and analysed in detail considering the maximum and the minimum water storage level of the Brazilian system. The next section will address the possibility for realization of a fully decarbonized energy system for the Brazilian power sector.

\subsection{Analysis of a $100 \%$ Renewable Electricity System for Brazil}

The possibility for realization of a $100 \%$ renewable electricity system for the Brazilian power sector in 2050 using EnergyPLAN is presented in this section. At this point, it is worth mentioning that the concept of a 100\% RES (also called as a "fully decarbonized energy system") used along of this work focus on the traditional analysis in which it is only considered the direct $\mathrm{CO}_{2}$ emissions (i.e. the emissions at the point of production) such as considered in [1,18,20]. However, according to [41], "all technologies, even those that produce carbon-free energy, have energy and emissions embedded in the production process and material". The indirect emissions are related, for example, to the manufacturing, construction and transport processes associated with the entire energy system. Therefore, we highlight the need to further assess the indirect $\mathrm{CO}_{2}$ emissions costs in a fully energy system as discussed for example by [41-43].

The fully renewable power supply system scenario presented in this paper is based on a set of assumptions [10,20,30,36,37]. At first, the future hydropower projects are expected to be dominated by run-of-river power plants with limited reservoir capacity due to a set of factors. This assumption is considered for modelling the $100 \%$ RES Brazilian model and the hydropower capacity expansion is projected considering the exploitation of a share of the remaining hydro potential and it is based on [10].

The overall wind power and CSP installed capacity are based on part of its available potential as proposed by [20]. Solar PV installed power capacity for northern and northwest is based on [30] and for southern according to [20]. The biomass installed capacity is also based on [30].

Despite the current high costs of the wave power, the overall potential of this source in Brazil is considered very high, particularly due to its vast coastline. The future wave power costs reduction is presumed based on [36]. Therefore, we assume an increase in the wave power installed capacity equal 
to half of the potential in the southern and southeast of the country [37]. Considering that there is no measured data available for hourly wave power, the monthly averages outputs are used based on the wave energy potential along the southern coast of Brazil, considering a capacity factor of 0.3 [37]. The remaining inputs for the EnergyPLAN model were established according to section 4 and are presented in Table A.1 (Appendix A).

The overall installed capacity reaches approximately $623 \mathrm{GW}$ for the $100 \%$ RES scenario in 2050. Annual power generation for the $100 \%$ RES scenario includes $49.99 \%$ from hydropower, followed by $26.81 \%$ from wind power. The remaining electricity supply mostly comes from solar PV $(1.90 \%)$ and rooftop PV (7.59\%) and biomass (5.81\%), but also from CSP (5.44\%) and wave power (2.46\%). EnergyPLAN analysis also reveals that the supply share of hydropower in the $100 \%$ RES scenario is higher but not much distant from the results obtained for COPPE $(41.58 \%)$ and Greenpeace $(42.48 \%)$. On the other hand, to meet the remaining needs of electricity without the use of traditional fossil-fuel based systems, mostly wind and solar power are expected to replace thermal power plants in 2050. It is worth mentioning that for 2050, the most important power source is still hydropower, as illustrated in Fig. 8. This power source should offer sufficient dispatchable power capacity to compensate fluctuations mainly from wind and solar power without the need for additional storage, as simulated and supported by [20]. However, we highlight the necessity to further assess these aspects in detail, considering the modelling of the intermittency nature of wind and solar power and its related impacts on the power system operation, especially in systems with a high share of hydropower, as is the case of Brazil.

The annual electricity production and the overall installed capacity for the $100 \%$ RES scenario in 2050 are illustrated in Fig. 8-a Fig. 8-b, respectively.

1000

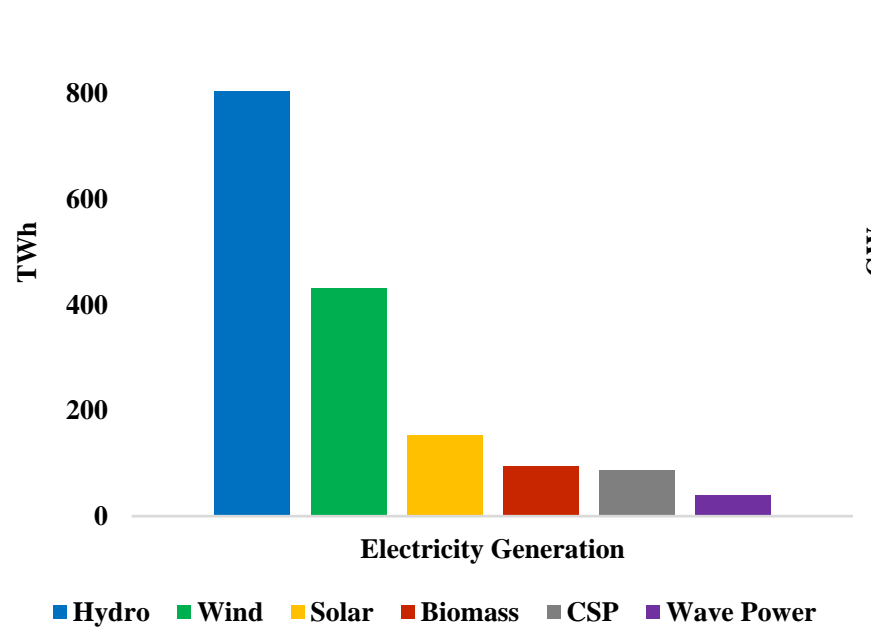

a)
250

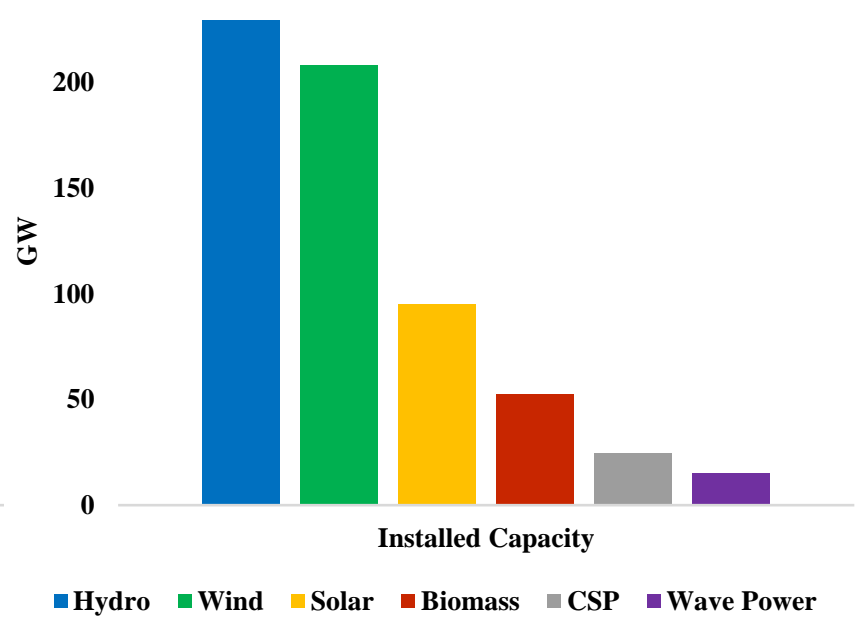

b)

Fig. 8. a) Annual electricity production for the 100\% RES scenario in 2050 and b) Overall installed capacity for the $100 \%$ RES scenario in 2050.

The hourly electricity production for the $100 \%$ RES scenario on a spring and autumn week, respectively, is illustrated in Fig. 9. 


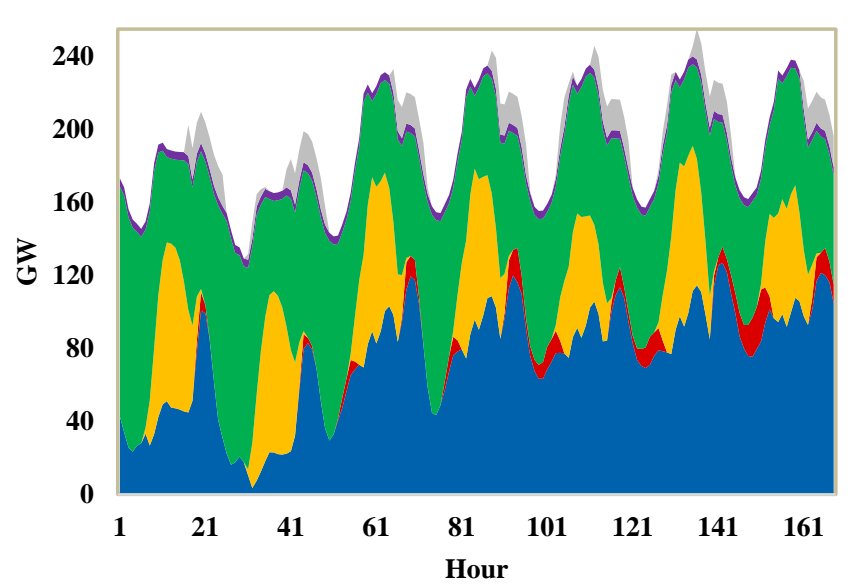

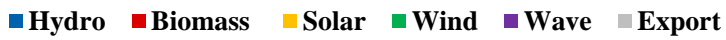

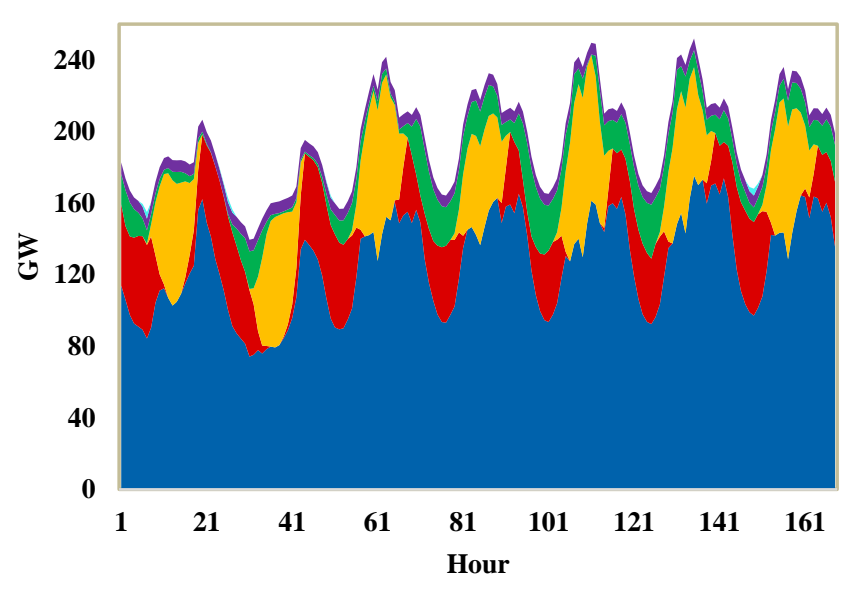

-Hydro $\square$ Biomass $\square$ Solar $\square$ Wind $\square$ Wave $\square$ Import

Fig. 9. Hourly electricity production for the 100\% RES scenario on a spring and autumn week, respectively.

The seasonal complementarity of hydro and wind power is also evident in Fig. 9 mostly for the spring season (see also Fig. 7). Although this complementarity is proven to be very relevant for COPPE and Greenpeace scenarios, for the $100 \%$ RES scenario this correlation is definitively essential, primarily because of the high shares of hydro and wind power in the electricity supply system projected for 2050.

It is worth mentioning that for the $100 \%$ RES scenario, the growth of VRE will strongly impact the excess electricity production which might be exported (see Fig. 9). The electricity that may be effectively exported (exported excess electricity production - EEEP) corresponds to $2.24 \%$ of the annual demand (35.16 TWh). The outcome of the high supply share of RES would be the existence of critical excess electricity production (CEEP), which refers to the full amount of electricity which is exceeding the electricity needs and the interconnection capacity. The simulation indicates that CEEP would represent $44.12 \mathrm{TWh}$ or $2.8 \%$ of the overall annual demand and would occur mainly during winter and spring season months. The annual electricity import occurs only to a very limited extent, corresponding to $0.04 \%(0.60 \mathrm{TWh})$ of the overall annual power demand and mostly happens during the summer season.

Conclusively, for the $100 \%$ RES scenario, there is a small risk of curtailment and electricity importations may occur. Furthermore, the existence of critical excess electricity production is expected to happen because of the high supply share of RES. The results also reveal how an increase in RES would add exportation potential to the power system, reducing the Brazilian external energy dependency. In general, exportations will mostly happen during the winter and spring seasons. Notwithstanding the decrease in hydropower production during these periods, the higher wind power production combined with lower demand requirements results on a higher exportation potential, which highlights complementarity of the resources as a key factor for achieving a high RES future in the country.

\subsection{Sensitivity Analysis}

The aim of this section is twofold. Firstly, the EnergyPLAN model is used to perform a sensitivity analysis of the future electricity scenarios addressed in the previous section. The sensitivity analysis is particularly important given the error obtained in the validation of the model and taking into account the variability of the renewable resources. Secondly, a reserve margin analysis is realized by taking into account all the scenarios evaluated.

Brazil experienced a severe drought that reduced reservoir water levels in 2001. Therefore, we collected available data from 2001 based on [17] to perform the simulations. The main objective of 
this analysis is to predict the behaviour of the power system for each scenario in the case of a critical 531 year with reduced water inflows.

532 Table 1 presents a set of risk indicators for each scenario (COPPE, Greenpeace and 100\% RES). The variations on the amount of electricity imported, EEPP, CEEP, load curtailment and the $\mathrm{CO}_{2}$ emissions for 2050, comparatively to the corresponding base scenarios are shown for COPPE and Greenpeace scenarios. As for $100 \%$ RES scenarios the indicators are expressed both as absolute values (TWh) and relative values against total demand (\%). The $\mathrm{CO}_{2}$ emissions indicator was expressed as the increased percentage comparatively to the base scenarios.

Table 1. Sensitivity analysis of future electricity scenarios for Brazil.

\begin{tabular}{|l|c|c|c|c|}
\multicolumn{1}{c|}{} & COPPE & Greenpeace & \multicolumn{1}{c|}{$\mathbf{1 0 0 \%}$ RES } \\
\cline { 2 - 5 } \multicolumn{1}{l|}{} & $\%$ & $\%$ & $\%$ & TWh \\
\hline $\begin{array}{l}\text { Expectricity import } \\
\text { Production - EEEP }\end{array}$ & 0 & 0 & 0.32 & 5.06 \\
\hline Critical Excess Electricity Production - CEEP & 0 & 0 & 2.23 & 35.16 \\
\hline Load Curtailment & & & & \\
\hline $\mathbf{C O}_{2}$ emissions (\% increased) & 0 & 0 & 2.81 & 44.12 \\
\hline
\end{tabular}

According to the results, the reduction in hydropower generation is fully compensated by thermal power plants for COPPE and Greenpeace scenarios. Additionally, there is no need for importation and exportation of electricity for both scenarios COPPE and Greenpeace. This result shows the high level of resilience of these scenarios for years of reduced water inflows. However, the additional electricity production from fossil fuel sources enhance the overall $\mathrm{CO}_{2}$ emissions by respectively $15.79 \%$ and $3.81 \%$ for COPPE and Greenpeace scenarios, comparatively to the base scenarios. Annual electricity production for the base and risk 100\% RES scenario is illustrated in Fig. 10-a. For the $100 \%$ RES scenario, the reduced water inflows were fully compensated by the biomass electricity production as showed in Fig. 10-a.

According to the EnergyPLAN results, it is possible to recognize that the reduced water inflows will strongly impact the overall amount of imported electricity for the $100 \%$ RES scenario. The considered interconnection system does not support the overall amount of required electricity, resulting in an annual Expected Energy Not Supplied (EENS) equal to 0.305 TWh $(0.02 \%$ of the overall annual demand). Import/export balance for the base and risk 100\% RES scenario are illustrated in Fig. 10-b. The simulation results also indicate that the highest hourly load curtailment would be nearby $14 \mathrm{GW}$. Therefore, power blackouts and electricity rationing might happen in real operation for the $100 \%$ RES scenario since failures in the system would occur if demand exceeds supply. The expansion of international interconnections, along with the possibility of other storage options or demand response strategies should be considered in future scenario analysis to mitigate shortfall risk mainly during summer and spring seasons. 


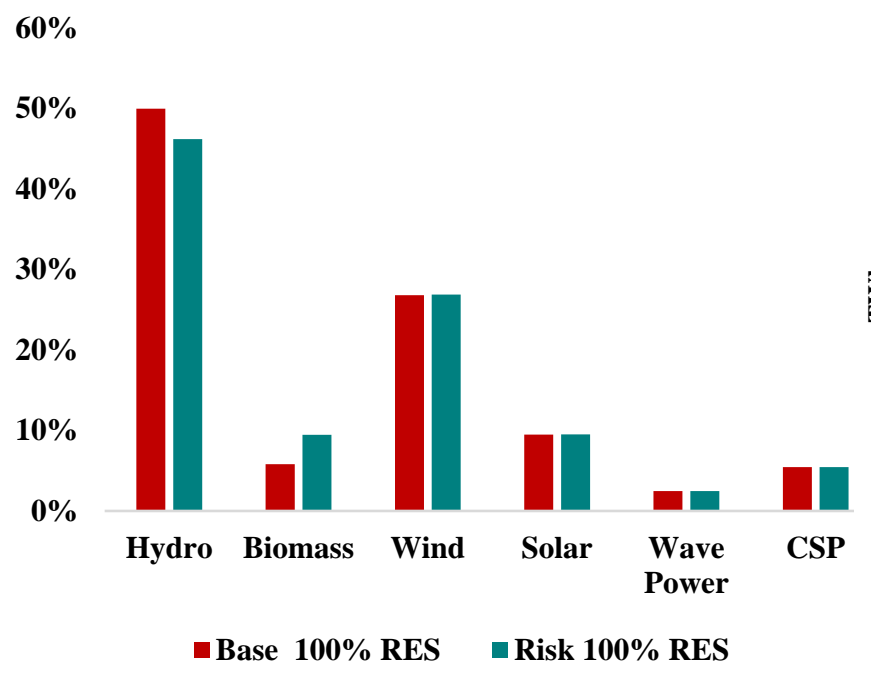

a)

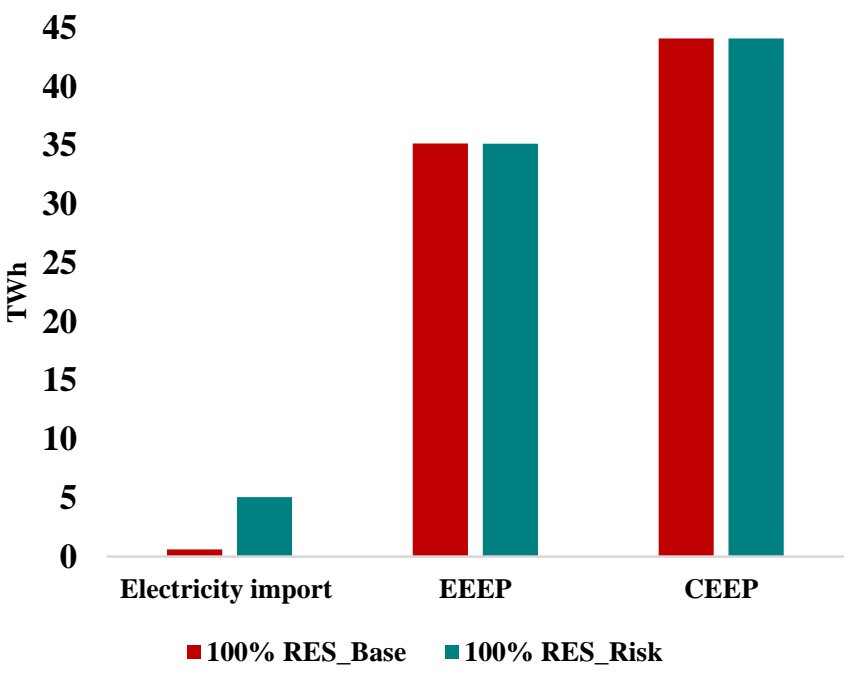

b)

563 Fig. 10. a) Annual electricity production for the base and risk 100\% RES scenario and $b$ ) Import/export balance for the base and risk 100\% RES scenario.

The sensitivity analysis was performed in this paper considering only the reductions in water inflows. Future studies will seek to develop additional sensitivity and risk analysis, varying the prices of fossil fuels (i.e. natural gas) and evaluate the impacts on the overall system costs for the COPPE and Greenpeace scenarios, for example.

Reserve Margin (RM) is defined as the difference between installed capacity and load. The installed generation capacity should be higher than the peak load to achieve the required generation adequacy target. In general, the higher the need for reliability, the higher the reserve margin. The proposed Brazilian EnergyPLAN model allows then to verify the reserve margin from the hourly results obtained in the simulation, as detailed in Fig. 11. In 2016, the overall installed capacity was 150.3 GW and the maximum measured peak load was $82 \mathrm{GW}$. This corresponds to a reserve margin of 68.3 GW and $45.4 \%$ of the installed capacity.

The installed capacity predicted by COPPE for 2050 is $460 \mathrm{GW}$. The resulting hourly load has an annual peak of $238 \mathrm{GW}$ for COPPE and Greenpeace scenarios. The reserve margin for COPPE is estimated to be approximately $222 \mathrm{GW}(48.2 \%$ of its installed capacity) and for Greenpeace, this value is approximately $274 \mathrm{GW}$ (53.5\% of its installed capacity) as illustrated in Fig. 11. Reserve margin was also estimated for the fully renewable electricity scenario resulting in the highest value $(385.5 \mathrm{GW})$ among all scenarios evaluated representing $61.9 \%$ of its overall installed capacity. This is mainly explained by the high share of variable electricity generation for the $100 \%$ RES scenario. Moreover, peak load usually occurs during summer months when wind power output is lower [17], posing additional challenges to the grid manager as load curtailment tends to emerge during this high load vs. low wind power availability periods. This additional reserve requirement should have important implications from the cost and risk points of view.

587 Therefore, the results obtained have enabled to conclude that for all scenarios evaluated the reserve 588 margin is expected to increase in 2050 , which can be explained mostly by the increasing reliance on RES of intermittent nature. 


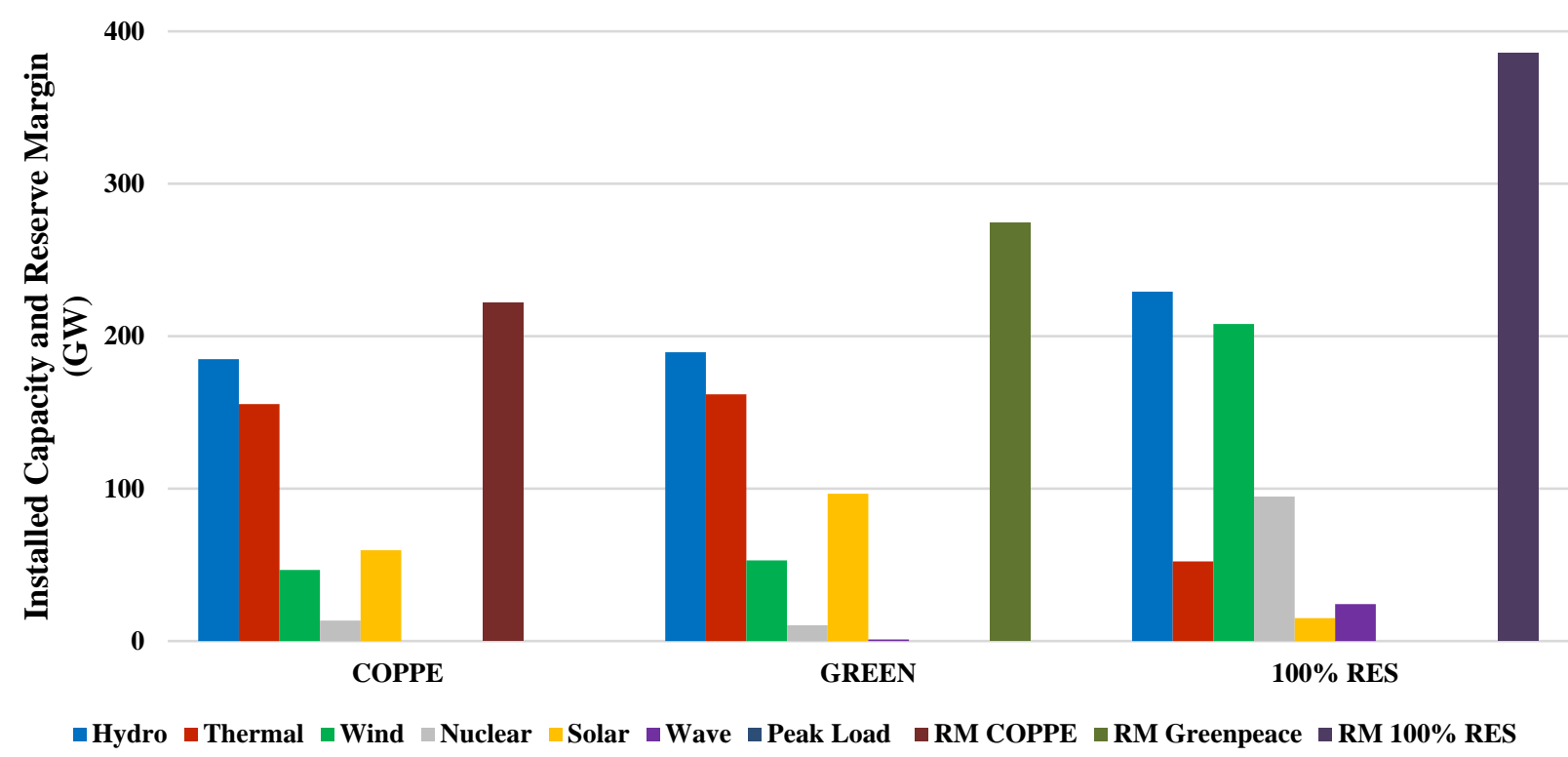

Fig. 11. Installed capacity and reserve margin for each scenario.

\subsection{Cost analysis}

This section aims to provide an overall socioeconomic analysis of the electricity system for all the scenarios evaluated (COPPE, Greenpeace and 100\% RES). The results are divided into the marginal costs (US\$/MWh), Levelized Cost of Electricity (US\$/MWh), total $\mathrm{CO}_{2}$ emissions (millions of tons - M). The annual costs include fuel, Operation and Maintenance (O\&M) and annualized investment costs based on the expected lifetime of power sources. Environmental analysis is undertaken estimating the total $\mathrm{CO}_{2}$ emissions for each scenario (millions of tons) and in terms of the allowances 599 costs (US\$).

600 Table 2 presents the techno-economical input data for the economic analysis in terms of capital 601 expenditure (CAPEX) in US\$/kW [36], O\&M costs (US\$/MWh) [36], fuel costs (US\$/MWh) [26, 602 27], $\mathrm{CO}_{2}$ emissions (ton/MWh) [36] and expected lifetime of each power source (years) [41].

Table 2. Techno-economical parameters for the economic analysis.

\begin{tabular}{lccccc} 
Power Source & $\begin{array}{c}\text { Expected Lifetime } \\
\text { (years) }\end{array}$ & CAPEX (US\$/kW) & $\begin{array}{c}\text { O\&M Costs } \\
\text { (US\$/MWh) }\end{array}$ & $\begin{array}{c}\text { Fuel Costs (US\$/ } \\
\text { MWh) }\end{array}$ & $\begin{array}{c}\text { CO }_{2} \text { Emissions } \\
\text { (ton/MWh) }\end{array}$ \\
\hline Photovoltaic & 25 & 2000 & 11.00 & - & - \\
Nuclear & 40 & 3500 & 11.00 & 7.62 & - \\
Hydro & 60 & 1750 & 2.00 & - & - \\
Wind & 30 & 1760 & 5.00 & - & - \\
Fuel Oil & 25 & 1200 & 22.00 & 67.56 & - \\
Solar CSP & 40 & 8500 & 30.00 & - & - \\
Rooftop PV & 25 & 3250 & 15.00 & - & 0.2786 \\
Natural Gas & 30 & 1025 & 12.00 & 51.20 & - \\
Biomass & 25 & 1350 & 11.00 & 14.88 & - \\
Small Hydro & 60 & 3250 & 13.50 & - & 0.3405 \\
Coal & 40 & 1650 & 13.00 & 13.26 & - \\
Wave Power & 30 & 5580 & 24.45 & - & \\
\hline
\end{tabular}

Fig. 12-a presents the annual costs for O\&M, fuel and $\mathrm{CO}_{2}$ costs for each scenario and Fig. 12-b illustrates the marginal and LCOE costs for each scenario. The forecast for the $\mathrm{CO}_{2}$ emissions allowances prices was based on [42] considering the average price between 2020-2050 (41.64 US\$/ton). The Weighted Average Cost of Capital (WACC) was considered equal to $9 \%$ and it was based on [36]. 


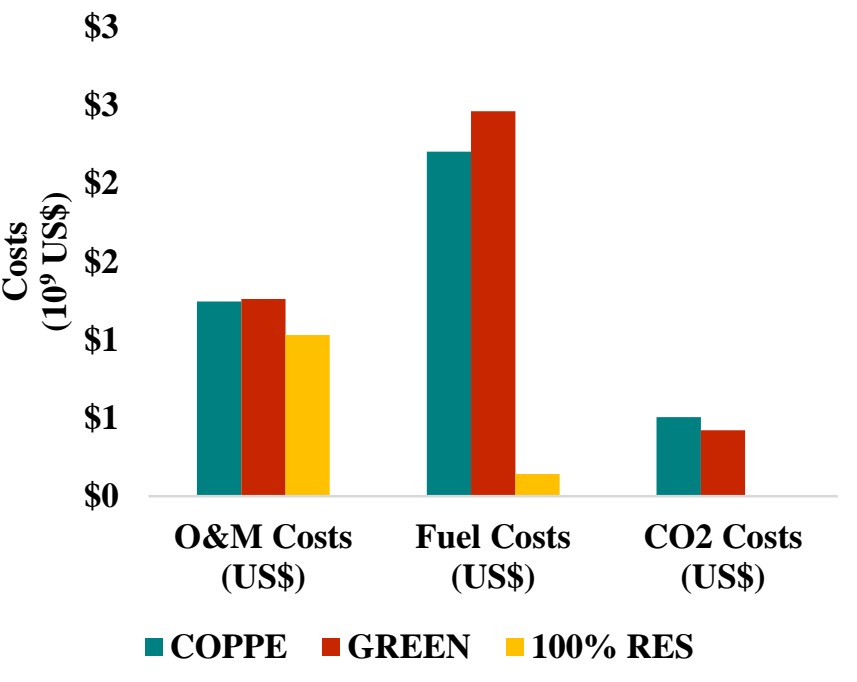

612

613 614

615 616 617 b) Marginal and LCOE costs for each scenario. lifetime. US\$).

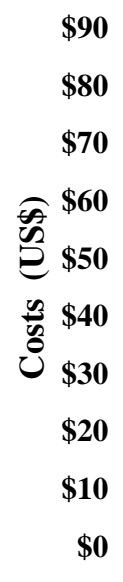

a)

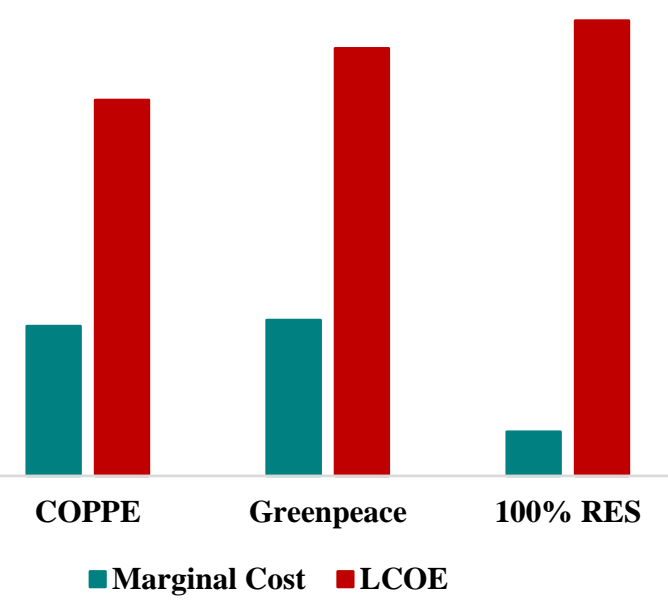

b)

Fig. 12. a) Total estimated $\mathrm{O} \& M$, fuel, and $\mathrm{CO}_{2}$ costs for each scenario for the year 2050 (US\$) and

The estimated total CAPEX, O\&M and fuel costs for each scenario are presented in Table 3. For the case of CAPEX, the value corresponds to the annualized cost of the total CAPEX over the expected

Table 3. Total estimated CAPEX, O\&M and Fuel Costs for each scenario for the year $2050\left(10^{9}\right.$

\begin{tabular}{|c|c|c|c|c|c|c|c|c|c|}
\hline & \multicolumn{3}{|c|}{ COPPE } & \multicolumn{3}{c|}{ Greenpeace } & \multicolumn{3}{c|}{ 100\% RES } \\
\hline Power Source & CAPEX & O\&M & Fuel & CAPEX & O\&M & Fuel & CAPEX & O\&M & Fuel \\
\hline Photovoltaic & 0.81 & 0.07 & - & 1.86 & 0.17 & - & 3.86 & 0.05 & - \\
\hline Nuclear & 3.72 & 0,89 & 0.61 & 2.74 & 0,68 & 0.47 & - & - & - \\
\hline Hydro & 12.43 & 1,16 & - & 13.82 & 1,22 & - & 20.94 & 0.15 & - \\
\hline Wind & 6.25 & 0,48 & - & 7.34 & 0,59 & - & 33.90 & 0.21 & - \\
\hline Fuel Oil & 0.46 & 0,39 & 1.21 & 1.10 & 0,89 & 2.72 & - & - & - \\
\hline Solar CSP & 3.95 & 0,43 & - & 5.53 & 0,79 & - & 19.20 & 0.24 & - \\
\hline Rooftop PV & 16.72 & 0,84 & - & 26.65 & 1,32 & - & 25.10 & 0.19 & \\
\hline Natural Gas & 4.82 & 3,67 & 15.64 & 8.46 & 4,45 & 19.00 & - & - & - \\
\hline Biomass & 5.24 & 2,04 & 2.76 & 3.36 & 1,65 & 2.23 & 5.24 & 0.10 & 0.14 \\
\hline Small Hydro & 2.80 & 0,64 & - & 1.57 & 0,49 & - & - & - & - \\
\hline Coal & 4.45 & 2,32 & 2.37 & 1.13 & 0,69 & 0.71 & - & - & - \\
\hline Wave Power & - & - & - & 0.54 & 0.04 & - & 8.15 & 0.09 & - \\
\hline TOTAL & $\mathbf{6 1 . 6 4}$ & $\mathbf{1 2 . 9 3}$ & $\mathbf{2 2 . 5 9}$ & $\mathbf{7 4 . 0 9}$ & $\mathbf{1 2 . 9 9}$ & $\mathbf{2 5 . 1 3}$ & $\mathbf{1 1 6 . 3 9}$ & $\mathbf{1 . 0 3}$ & $\mathbf{0 . 1 4}$ \\
\hline
\end{tabular}

The marginal costs (US\$/MWh), Levelized Cost of Electricity (US\$/MWh), total $\mathrm{CO}_{2}$ emissions (millions of tons and $\mathrm{tCO}_{2} / \mathrm{MWh}$ ), and the percentage of RES for each scenario evaluated are presented in Table 4. Marginal costs were calculated considering the sum of the annual cost of O\&M, fuel and $\mathrm{CO}_{2}$ emissions. Historically, the costs to produce electricity have been evaluated using the Levelized Cost of Electricity [15]. LCOE is considered as a reference to competitiveness by the International Energy Agency (IEA). The LCOE considers also the investment costs in an annualized base whereas the marginal costs do not take into consideration the capital expenditure.

Table 4. Results for marginal cost, LCOE and $\mathrm{CO}_{2}$ emissions for each scenario.

\begin{tabular}{lccccc}
\hline & \% RES & $\begin{array}{c}\text { Marginal Cost } \\
\text { (US\$/MWh) }\end{array}$ & $\begin{array}{c}\text { LCOE } \\
\text { (US\$/MWh) } / \mathbf{M W h}\end{array}$ & $\begin{array}{c}\mathbf{C O}_{2} \text { emissions } \\
\text { (millions of } \\
\text { tons) }\end{array}$ & $\begin{array}{c}\mathbf{C O}_{2} \text { emissions } \\
(\mathbf{t C O} / \mathbf{M W h})\end{array}$ \\
\hline Scenario 1 (COPPE) & 62.62 & 25.99 & 65.22 & 128.6 & 0.082 \\
Scenario 2 (Greenpeace) & 66.22 & 27.02 & 74.17 & 104.4 & 0.066
\end{tabular}


The overall installed power generation capacity is about $460 \mathrm{GW}$ in scenario 1 (COPPE) whereas for scenario 2 (Greenpeace) the installed capacity is equal to $512.4 \mathrm{GW}$. Greenpeace also considers a higher installed capacity of natural gas for 2050 comparatively to COPPE. For this reason, the capital expenditure for Greenpeace is $19.1 \%$ higher than for COPPE scenario. We can also note that the fuel costs for Greenpeace is $11.8 \%$ higher than for COPPE, which comes to the higher amount of natural gas and fuel oil used for electricity production for Greenpeace scenario.

Thus, regardless of the lower O\&M costs of RES, the marginal cost obtained under Greenpeace scenario is higher than the one obtained for COPPE, mainly due to the higher fuel costs in the first one. The avoided $\mathrm{CO}_{2}$ emissions brought by the increasing share of RES and its valuation are not enough to compensate the high cost of fossil fuel in Greenpeace scenario. It is worth mentioning that although LCOE for the Greenpeace scenario is $12.07 \%$ higher than the one for COPPE, it allows to reduce $\mathrm{CO}_{2}$ emissions by $23.18 \%$.

For the $100 \%$ RES scenario, the marginal cost (7.67 US\$/MWh) is considerably reduced comparatively to COPPE and Greenpeace scenarios mainly due to the lower O\&M costs of RES and because $\mathrm{CO}_{2}$ emissions costs are zero. Notwithstanding, because of its high CAPEX, the LCOE for the $100 \%$ RES scenario is respectively $21.1 \%$ and $6.5 \%$ higher comparatively to COPPE and Greenpeace scenarios. However, it would allow to reach a fully decarbonized electricity system.

The current Brazil's electricity grid emission factor is slightly higher than $0.135 \mathrm{tCO} / \mathrm{MWh}^{2}$ [4] . According to the results presented in Table 4, the estimated emission factor for COPPE $(0.082$ $\left.\mathrm{tCO}_{2} / \mathrm{MWh}\right)$ and Greenpeace $\left(0.066 \mathrm{tCO}_{2} / \mathrm{MWh}\right)$ are very similar and decrease $39.4 \%$ and $50.8 \%$ comparatively to the current emissions factor value.

\subsection{Discussion}

Economic and environmental analyses of the overall system were undertaken in order to complement the technical analysis of the three scenarios analysed. According to the results, $\mathrm{CO}_{2}$ emissions are $23.18 \%$ lower for Greenpeace comparatively to COPPE scenario. This, however, comes with an increase of $12.07 \%$ in the levelized cost of electricity. The indicate that large RES scenarios tend to result on higher LCOE but can also lead to the full decarbonization of the electricity sector, which represents a conflicting trade-off between direct cost and environment. At this stage, it is important to recall that LCOE does not fully take into account the main challenges posed by the intermittent characteristic of RES. As such, aspects related to the difficulties of using LCOE for RES of intermittent characteristics (as discussed for example by [44]) in particular in a large hydro system and even the issue of energy independence mainly related to natural gas importations of Brazil, must be further explored.

According to COPPE and Greenpeace scenarios evaluation, the results obtained under the technical analysis showed that thermal power plants are intended to play an essential role in the next years, mainly between September and December, due to the lower hydropower storage level. Thus, according to the scenarios evaluated, non-RES technologies (primarily thermal power plants) will continue to develop in order to provide a safer and reliable generation expansion plan in the scenarios predicted by COPPE and Greenpeace. The results also indicate that the high share of several complementary non-hydro RES is expected to diminish the dependency on hydropower and result in a least-cost solution in the future. Furthermore, it can be noted that the increase of solar power will have a significant impact on thermal power output, primarily during peak sun-hours. Wind power also plays a key role in the future primarily between July and November.

Hydropower remains the most important power source for all scenarios regarding the overall electricity production in 2050 with a supply share varying between $41.58 \%$ and $49.99 \%$. Solar power contributes between $6.17 \%$ and $14.93 \%$, wind power between $7.6 \%$ and $26.81 \%$ and wave power between $0.11 \%$ and $2.46 \%$. The remaining electricity supply is expected to come from biomass and thermal generation. However, the hourly results allow to highlight the higher contribution of wind 
power primarily in spring and winter seasons when the water storage levels of the overall system are risky. It is worth mentioning that although non-dispatchable, the higher contribution of wind power from June to December occurs mainly because of the more favourable wind-profile in this period of time (see Fig. 7).

682 The total renewable electricity production for 2050 is expected to decrease from $81.7 \%$ in 2016 to of wind and solar power in the future scenarios are not sufficient to compensate the decrease (in percentage of the current share) of the hydropower source. On the other side, although the projected power demand for 2050 is expected to be about three times higher than the demand of 2016, the results show that the overall $\mathrm{CO}_{2}$ emissions (in millions of tons) are expected to less than double the current emissions. The sensitivity analysis revealed that there is no need for importation and exportation of electricity for both scenarios COPPE and Greenpeace even under low water availability. As for the $100 \%$ risk scenario, a reduction of the water availability would lead to an increase of the importation values and could even result on a few curtailment moments, which calls for further studies on demand/supply balance and short-term storage.

It is worth mentioning that the largest part of the Brazilian remaining hydro potential is located in the Amazon River basin (Northeast region) near indigenous lands and/or protected areas. Therefore, the challenges of exploiting the remaining potential of hydropower are related primarily to social and environmental issues. Although these social and environmental impacts are out of the scope of this work, it is worth recalling that these aspects cannot be considered to be negligible in what concerns the Brazilian power planning as showed in works such as [2] and [45].

In light of what was written in Section 4, due to technical limitations of the EnergyPLAN software, it was not considered the interconnection restrictions between Brazilian subsystems on the simulations. While it is beyond the scope of our current analysis, it would be relevant to consider the impact of internal Brazilian interconnections in future studies. In addition, considering that the high share of wind power occurs in the Northwest of the country, this would imply in possible future problems related to transmission restrictions. Therefore, in light with [15], a significant increase in the power transmission capacity of the Northwest subsystem would be required in order to enhance its operational flexibility in situations of low storage availability (in which the interconnection would be needed for electricity importation) and also for exportation of wind energy during specific periods of the year. The possibility of additional international interconnections should be further evaluated considering the effective exportation potential, the market interest and the bargaining power, as discussed for example by [46].

Several uncertainties are evolved in the long-term 2050 horizon planning process, e.g., economic growth, government policies, technological development, energy efficiency and demand response measures. These features together might define the pathways in which the energy mix will be deployed in the future. The possibility of future deployment schedules of energy prices to meet the peak demand can also lead to reductions in the actual expansion requirements. The smart grid deployment might also develop a key role in implementing the energy transition through the high integration of RES technologies. The prospect for future technological developments such as storage technologies, i.e., vehicle-to-grid, are in fact expected to play a key role in the long-term, contributing to accommodate the critical excess of electricity production. Additionally, the availability of wind and solar energy is strongly climate dependent. However, if the electricity generated by this VRE could be temporarily stored in the short and long term, this problem would be minimized. The vehicleto-grid technology could support the grid and create a more reliable, responsive and stable electrical system. The technologies' deployment depends strongly on government financial incentives and new political regulatory goal but should not be overlooked on long-term planning problems.

Specifically, for the Brazilian electricity sector, a more diverse energy mix is needed in order to achieve a low carbon-based energy system and a more sustainable power sector. The ambitious transition on moving toward a sustainable future is clearly considered a great energy challenge for 
Brazil. However, if we desire to surpass the economic, environmental and social impacts of fossil fuel exploitation these measures are necessary and may set a landmark for future generations.

\section{Conclusions}

This work aimed to contribute to the evaluation of future scenarios for the Brazilian power sector, resourcing to EnergyPLAN model to undertake the simulations. In contrast to traditional long-term models characterized by a reduced number of time slices, EnergyPLAN simulates a single year in hourly time-steps. This is considered an advantage from the model analysis in comparison with traditional long-term energy planning tools. The hypothesis of obtaining hourly results for long-term electricity planning could be considered an unrealistic assumption because it is improbable that future electricity generation could achieve exactly the value obtained by the hourly simulation model. Nonetheless, the real usefulness of obtaining results on an hourly basin is that it is possible to analyse more accurately the probable implications of seasonal patterns in electricity use and the need of using storage technologies in the future, for instance.

Conclusively, we refer to the research questions proposed in the introduction:

How can the Brazilian electricity system be modelled in the EnergyPLAN computer model?

This paper proposed a long-term EnergyPLAN model for the Brazilian electricity system. The model was validated considering a reference year and then future electricity scenarios were analysed. The results obtained by the EnergyPLAN model were then compared to the published scenarios for 2050. Given the size and complexity of Brazilian electricity system, the model required some simplifications for example in what concerns regional demand and transmission restrictions. Considering the obtained results discussed along of this paper, the proposed Brazilian EnergyPLAN model although simplified, was shown to be suitable to evaluate future scenarios for electricity generation. In addition, the methodology applied in this work might be transferable to evaluate other power systems.

\section{Can a 100\% renewable energy system be achieved by 2050 for Brazil?}

The $100 \%$ RES scenario is found to be theoretically possible but a substantial increase in the installed capacity would be required to support the grid mainly during periods of peak demand (6 p.m. to 10 p.m.). Our findings also demonstrated that the fully decarbonized energy system may be achieved but the cost would tend to increase. The increasing cost of the LCOE for the 100\% RES scenario is estimated to be $21.1 \%$ and $6.5 \%$ higher comparatively to COPPE and Greenpeace scenarios, respectively. This results both from the high CAPEX cost of most renewable technologies comparatively to natural gas options and from the required higher reserve margin, as dispatchable sources are necessary in order to provide a high level of security and reliability to the Brazilian power system. There is a small risk of curtailment and electricity importations may occur for the fully decarbonized system as illustrated in the sensitivity analysis. The outcome of the high supply share of RES would also be the existence of critical excess electricity production (CEEP), which refers to the full amount of electricity which is exceeding the electricity needs and the interconnection capacity. The transition to a $100 \%$ RES also contributes to the goal of reducing the imports of natural gas from Bolivia and consequently moving towards the Brazilian energy independence and increasing energy security.

We conclude that RES could contribute significantly to the decarbonization of power systems, even for regions or countries for which demand is still expected to increase during the next years, as is the case of Brazil. The simulation exercise showed that this may be achieved but the cost would tend to increase. However, the $100 \%$ RES scenario should be further explored considering both the use of an optimization approach and the prospects for the electricity sector such as the inclusion of storage systems, new interconnections capacity and demand-side management strategies. Additionally, future works should consider other scenarios analysis and compare to the ones presented in this research paper. We also suggest the inclusion of more sectors (beyond the electricity sector) such as the heating, cooling and transportation to analyse the transition to a fully decarbonized energy system in 
777 Brazil. This should provide more achievable and affordable solutions to the transition of the entire 778 energy system into future renewable and sustainable energy solutions.

779 Last, but not least, we highlight that many other pathways towards achieving a fully decarbonized 780 energy system for Brazil by 2050 can be proposed, but for each pathway, a set of significant changes 781 away from the current energy system would be required. 
784 Table A.1. EnergyPLAN input data for the reference model (2016) e for the future scenario (2050).

\begin{tabular}{|c|c|c|c|c|}
\hline \multicolumn{5}{|c|}{ Electricity Demand } \\
\hline & $\begin{array}{c}\text { Reference } \\
\text { (2016) }\end{array}$ & $\begin{array}{l}\text { Coppe } \\
(2050) \\
\end{array}$ & $\begin{array}{c}\text { Greenpeace } \\
(2050)\end{array}$ & $100 \%$ RES \\
\hline Electricity Demand (TWh/year) & 541.29 & $1,571.55$ & $1,571.55$ & $1,571.55$ \\
\hline Fixed Import/Export (TWh/year) & 0.179 & 0.179 & 0.179 & 0.179 \\
\hline Total Electricity Demand (TWh/year) & 541.47 & $1,571.73$ & $1,571.73$ & $1,571.73$ \\
\hline \multicolumn{5}{|c|}{ Electricity Supply } \\
\hline Dammed Hydro Water Supply (TWh/year) & 186.03 & 204.63 & 204.63 & 204.63 \\
\hline Storage for Dammed Hydro (GWh) & 96,145 & $105,759.5$ & $105,759.5$ & $105,759.5$ \\
\hline Dammed Hydro Power (MW) & 44,586 & 53,385 & 53,846 & 53,846 \\
\hline River Hydro (MW) & 52,340 & 131,529 & 135,683 & 175,300 \\
\hline Nuclear (MW) & 1,990 & 13,412 & 10,412 & 0 \\
\hline Thermal Power (coal, oil, gas) (MW) & 14,147 & 103,230 & 123,305 & 0 \\
\hline Biomass (MW) & 27,128 & 52,287 & 38,584 & 52,287 \\
\hline Wind (Northwest and North) (MW) & 8,210 & $36,838.33$ & $41,851.36$ & 132,000 \\
\hline Wind (South) (MW) & 1,886 & $9,631.49$ & $5,555.82$ & \multirow{2}{*}{76,000} \\
\hline Wind (Southwest and Mid-west) (MW) & 28 & 149.18 & $5,555.82$ & \\
\hline Solar Power (Northwest and North) (MW) & 15 & $38,830.68$ & $63,061.22$ & 38,830 \\
\hline Solar Power (South) (MW) & 4 & $10,353.66$ & $16,814.39$ & \multirow{2}{*}{56,000} \\
\hline Solar Power (Southwest and Mid-west) (MW) & 4 & $10,353.66$ & $16,814.39$ & \\
\hline Wave Power (MW) & 0 & 0 & 1,000 & 15,000 \\
\hline CSP Solar Power (MW) & 0 & $*$ & $*$ & 24,300 \\
\hline TOTAL INSTALLED CAPACITY (GW) & 150.34 & 460.00 & 512.48 & 623.56 \\
\hline Pump Back Capacity (MW) & 137.9 & 137.9 & 137.9 & 137.9 \\
\hline International Interconnection Capacity (GW) & 17 & 17 & 17 & 17 \\
\hline
\end{tabular}

*Included in Solar Power (Northwest and North), Solar Power (South) and Solar Power (Southwest and Mid-west) due to EnergyPLAN simulation restrictions.

\section{References}

[1] Khoodaruth A, Oree V, Elahee MK, Clark WW. Exploring options for a $100 \%$ renewable energy system in Mauritius by 2050. Util Policy 2017;44:38-49. doi:10.1016/j.jup.2016.12.001.

[2] Santos MJ, Ferreira P, Araújo M, Portugal-Pereira J, Lucena AFPP, Schaeffer R. Scenarios for the future Brazilian power sector based on a multi-criteria assessment. J Clean Prod 2018;167:938-50. doi:10.1016/j.jclepro.2017.03.145.

[3] Reis LB, Santos ED. Energia Elétrica e Sustentabilidade. Second ed. São Paulo: Manole; 2014.

[4] Dantas GDA, de Castro NJ, Brandão R, Rosental R, Lafranque A, Castro NJ De, et al. Prospects for the Brazilian electricity sector in the 2030s: Scenarios and guidelines for its transformation. Renew Sustain Energy Rev 2017;68:997-1007. doi:10.1016/j.rser.2016.08.003.

[5] IMF - International Monetary Fund. World Economic Outlook: Gaining Momentum? World $\begin{array}{llll}\text { Econ } & \text { Outlook } & \text { April 2017:237. }\end{array}$ https://www.imf.org/en/Publications/WEO/Issues/2017/04/04/world-economic-outlook-april2017.

[6] Brijs T, van Stiphout A, Siddiqui S, Belmans R. Evaluating the role of electricity storage by considering short-term operation in long-term planning. Sustain Energy, Grids Networks 2017;10:104-17. doi:10.1016/j.segan.2017.04.002.

[7] Lund H. Renewable Energy Systems: A Smart Energy Systems Approach to the Choice and Modeling of 100\% Renewable Solutions: Second Edition. 2014. doi:10.1016/C2012-0-072730 . 
IEA.

Technology

Roadmap.

Hydropower.

OECD/IEA

2012:68. doi:10.1007/SpringerReference_7300.https://www.iea.org/publications/freepublications/publ ication/2012_Hydropower_Roadmap.pdf (accessed March 5, 2018).

[9] Barbosa L de SNS, Orozco JF, Bogdanov D, Vainikka P, Breyer C. Hydropower and Powerto-gas Storage Options: The Brazilian Energy System Case. Energy Procedia 2016;99:89-107. doi:10.1016/j.egypro.2016.10.101.

[10] Larentis DG, Collischonn W, Olivera F, Tucci CEM. Gis-based procedures for hydropower potential spotting. Energy 2010;35:4237-43. doi:10.1016/j.energy.2010.07.014.

[11] Child M, Breyer C. The Role of Energy Storage Solutions in a 100\% Renewable Finnish Energy System. Energy Procedia 2016;99:25-34. doi:10.1016/j.egypro.2016.10.094.

[12] de Lucena AFP, Szklo AS, Schaeffer R, de Souza RR, Borba BSMC, da Costa IVL, et al. The vulnerability of renewable energy to climate change in Brazil. Energy Policy 2009;37:879-89. doi:10.1016/J.ENPOL.2008.10.029.

[13] Brazilian Electricity Regulatory Agency. Generation Database (BIG). ANEEL 2018. http://www2.aneel.gov.br/aplicacoes/capacidadebrasil/capacidadebrasil.cfm (accessed March 9, 2018).

[14] EPE. Brazilian Energy Balance 2016: base year 2015. Brazilian Energy Res 2016:292. https://ben.epe.gov.br/ (accessed March 5, 2018).

[15] EPE. Plano Decenal de Expansão de Energia 2026. Ministério Minas E Energ 2017:264. http://www.epe.gov.br/pt/publicacoes-dados-abertos/publicacoes/plano-decenal-deexpansao-de-energia-pde (accessed February 10, 2018).

[16] Zambon RC. A operação dos reservatórios e o planejamento da operação hidrotérmica do Sistema Interligado Nacional. Rev USP - Supt Comun Soc Da Univ São Paulo 2015:133-44. doi:10.11606/issn.2316-9036.v0i104p133-144.

[17] ONS. ONS 2018. http://www.ons.org.br/pt/paginas/resultados-da-operacao/historico-daoperacao (accessed September 20, 2017).

[18] Ćosić B, Krajačić G, Duić N. A 100\% renewable energy system in the year 2050: The case of Macedonia. Energy 2012;48:80-7. doi:10.1016/j.energy.2012.06.078.

[19] Lund H. Renewable Energy Systems: a Smart Energy Systems Approach to the Choice and Modeling of 100\% Renewable Solutions. 2014. doi:0.3303/CET1439001.

[20] Gils HC, Simon S, Soria R. 100\% Renewable energy supply for Brazil-The role of sector coupling and regional development. Energies 2017;10. doi:10.3390/en10111859.

[21] Lund $H$. Renewable heating strategies and their consequences for storage and grid infrastructures comparing a smart grid to a smart energy systems approach. Energy 2018;151:94-102. doi:10.1016/j.energy.2018.03.010.

[22] Thellufsen JZ, Lund H. Roles of local and national energy systems in the integration of renewable energy. Appl Energy 2016;183:419-29. doi:10.1016/j.apenergy.2016.09.005.

[23] Bačeković I, Østergaard PA. A smart energy system approach vs a non-integrated renewable energy system approach to designing a future energy system in Zagreb. Energy 2018. doi:10.1016/j.energy.2018.05.075.

[24] Bačeković I, Østergaard PA. Local smart energy systems and cross-system integration. Energy 2018;151:812-25. doi:10.1016/j.energy.2018.03.098.

[25] Thellufsen JZ, Lund H. Cross-border versus cross-sector interconnectivity in renewable energy systems. Energy 2017;124:492-501. doi:10.1016/j.energy.2017.02.112.

[26] EnergyPLAN - Advanced energy system analysis computer model 2017. http://www.energyplan.eu/ (accessed October 9, 2017).

[27] Østergaard PA. Reviewing EnergyPLAN simulations and performance indicator applications in EnergyPLAN simulations. Appl Energy 2015;154:921-33. 
doi:10.1016/j.apenergy.2015.05.086.

[28] Fernandes L, Ferreira P. Renewable energy scenarios in the Portuguese electricity system. Energy 2014;69:51-7. doi:10.1016/j.energy.2014.02.098.

[29] EPE. Brazilian Energy Balance 2017: base year 2016. Energy Res Off 2017:296. https://ben.epe.gov.br/ (accessed March 5, 2018).

[30] PCE. Cenários para a Matriz Elétrica 2050: Aporte ao debate energético nacional e ao planejamento participativo de longo prazo - PCE Brasil 2050 2015:78. http://www.nextrans.com.br/wp-content/uploads/2015/03/Energia-Cenarios-2050.pdf (accessed October 5, 2017).

[31] CIER. Síntesis Informativa Energetica de los Países de la CIER 2015. Información del sector energético en países de América del Sur, América Central y El Caribe - Datos del año 2014 2015:37. www.cier.org (accessed October 1, 2017).

[32] EPE. Calculadora 2050 2017. http://calculadora2050brasil.epe.gov.br/calculadora.html\# (accessed March 5, 2018).

[33] Pfenninger S, Staffell L. Renewables Ninja 2016. www.renewables.ninja (accessed November 14, 2017).

[34] Pfenninger S, Staffell L. Long-term patterns of European PV output using 30 years of validated hourly reanalysis and satellite data. Energy 2016;114:1251-65. doi:10.1016/j.energy.2016.08.060.

[35] Staffell L, Pfenninger S. Using Bias-Corrected Reanalysis to Simulate Current and Future Wind Power Output. Energy 2016;114:1224-39. doi:10.1016/j.energy.2016.08.068.

[36] Metodologia para elaboração e validação dos cenários elétricos - Plataforma Cenários Energéticos 2015:36. http://viex-americas.com/cortex/wwf/pce/metodologia/ (accessed November 17, 2017).

[37] Assis LE, Beluco A, de Almeida LEB. On the wave energy potential along the southern coast of Brazil. Int J Energy Environ 2014;5:59-66.

[38] Lund H. EnergyPLAN - documentation 2017. http://www.energyplan.eu/.

[39] Corrêa Da Silva R, De Marchi Neto I, Silva Seifert S. Electricity supply security and the future role of renewable energy sources in Brazil. Renew Sustain Energy Rev 2016;59:328-41. doi:10.1016/j.rser.2016.01.001.

[40] Miranda R, Soria R, Schaeffer R, Szklo A, Saporta L. Contributions to the analysis of "Integrating large scale wind power into the electricity grid in the Northeast of Brazil" [Energy 100 (2016) 401-415]. Energy 2017;118:1198-209. doi:10.1016/J.ENERGY.2016.10.138.

[41] Pinto de Moura GN, Loureiro Legey LF, Balderrama GP, Howells M. South America power integration, Bolivian electricity export potential and bargaining power: An OSeMOSYS SAMBA approach. Energy Strateg Rev 2017;17:27-36. doi:10.1016/j.esr.2017.06.002.

[42] Luckow P, Stanton E, Fields S, Biewald B, Jackson S, Fisher J, et al. 2015 Carbon Dioxide Price Forecast 2015:39. http://www.synapse-energy.com/about-us/blog/synapse-releases2015-carbon-dioxide-price-forecast (accessed September 20, 2017).

[43] Rochedo PRR, Costa IVL, Império M, Hoffmann BS, Merschmann PRDC, Oliveira CCN, et al. Carbon capture potential and costs in Brazil. J Clean Prod 2016;131:280-95. doi:10.1016/j.jclepro.2016.05.033.

[44] Reichenberg L, Hedenus F, Odenberger M, Johnsson F. The marginal system LCOE of variable renewables - Evaluating high penetration levels of wind and solar in Europe. Energy 2018;152:914-24. doi:10.1016/J.ENERGY.2018.02.061.

[45] Portugal-Pereira J, Köberle AC, Soria R, Lucena AFP, Szklo A, Schaeffer R. Overlooked impacts of electricity expansion optimisation modelling: The life cycle side of the story. Energy 2016;115:1424-35. doi:10.1016/J.ENERGY.2016.03.062. 
906

907

908

909

910
[46] de Moura GNP, Legey LFL, Howells M. A Brazilian perspective of power systems integration using OSeMOSYS SAMBA - South America Model Base - and the bargaining power of neighbouring countries: A cooperative games approach. Energy Policy 2018;115:470-85. doi:10.1016/J.ENPOL.2018.01.045. 